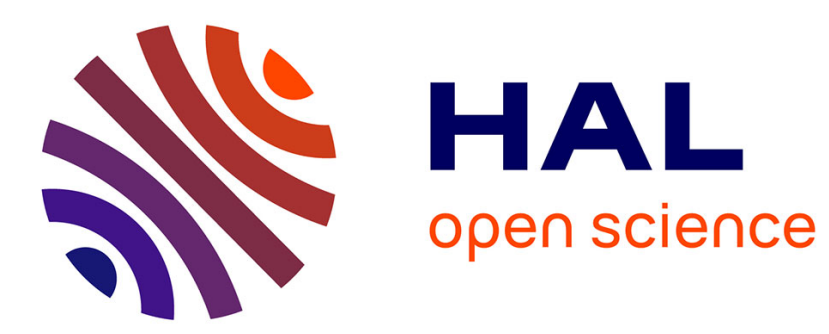

\title{
Tunable electrodeposition of Sn and Sn-based alloys using ionic liquids
}

\author{
D. Liu, Henri Groult, L. Gaillon, C. Rizzi, N. Soulmi, C. M. Julien, E. Briot, \\ D. Krulic
}

\section{- To cite this version:}

D. Liu, Henri Groult, L. Gaillon, C. Rizzi, N. Soulmi, et al.. Tunable electrodeposition of Sn and Snbased alloys using ionic liquids. Journal of Solid State Electrochemistry, 2015, 19 (9), pp.2517-2532. 10.1007/s10008-015-2809-8 . hal-01539725

\section{HAL Id: hal-01539725 https://hal.sorbonne-universite.fr/hal-01539725}

Submitted on 15 Jun 2017

HAL is a multi-disciplinary open access archive for the deposit and dissemination of scientific research documents, whether they are published or not. The documents may come from teaching and research institutions in France or abroad, or from public or private research centers.
L'archive ouverte pluridisciplinaire HAL, est destinée au dépôt et à la diffusion de documents scientifiques de niveau recherche, publiés ou non, émanant des établissements d'enseignement et de recherche français ou étrangers, des laboratoires publics ou privés. 


\title{
Tunable electrodeposition of Sn and Sn-based alloys using ionic liquids
}

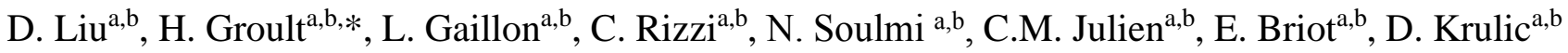 \\ ${ }^{a}$ Sorbonne Universités, UPMC Univ Paris 06, UMR 8234, Laboratoire PHENIX, F-75005, \\ Paris France \\ ${ }^{b}$ CNRS, UMR 8234, Laboratoire PHENIX, F-75005, Paris France \\ *Corresponding author - Email: henri.groult@upmc.fr
}

\begin{abstract}
-
The electrochemical behavior of $S n(I I)$ was studied at $25^{\circ} \mathrm{C}$ in three different room temperature ionic liquids [1-ethyl-3-methylimidazolium dicyanamide (EMI-DCA), 1-butyl-1methylpyrrolidium bis(trifluoromethanesulfonyl)imide (BMP-NTf 2$)$, 1-ethyl-3-methylimidazo lium bis(trifluoromethanesulfonyl)imide (EMI-NTf $\left.f_{2}\right)$ ]. The Sn(II) was introduced into EMI-NTf $f_{2}$ by anodic dissolution with a current efficiency of almost $100 \%$. The diffusion coefficient of Sn(II) was compared in three ionic liquids at different temperatures. In addition, the morphology of Sn deposits on the inert substrate Mo obtained from three ionic liquids at $25^{\circ} \mathrm{C}$ was characterized. This study also shows that the copper-tin alloy could be achieved in EMI$N T f_{2}$ by the electrodeposition method and subsequent thermal treatment.
\end{abstract}

Keywords: Ionic Liquids, Tin, Tin alloys, Electrodeposition, Electrochemistry

\section{INTRODUCTION}

Room temperature ionic liquids (denoted ILs or RTILs) [1-4] are widely used in various electrochemical domains notably as electrolyte for electrodeposition of various metals including noble metals [5-14], in batteries [15-21], in dye sensitized solar cells [16, 22], etc. Compared with conventional aqueous electrolytes, RTILs offer several advantages for practical uses such as negligible vapor pressure, higher thermal stability, higher ionic conductivity and wider electrochemical windows allowing deposition of metals [17, 23-29]. Moreover, aprotic RTILs prevent the problem linked to the hydrogen evolution which usually occurs in aqueous solutions and results in a decrease of the current efficiency. Depending on the nature of the cations and anions, the physico-chemical properties in RTILs such as conductivity, solubility, deposition potential, etc. could differ drastically. Electrodeposition of $\mathrm{M}-\mathrm{Sn}$ alloys (with $\mathrm{M}=$ $\mathrm{Ni}, \mathrm{Cu}, \mathrm{Co}$ ) which are usually obtained at high temperature for instance in molten $\mathrm{LiCl}-\mathrm{KCl}$ as 
published recently $\left(\geq 400^{\circ} \mathrm{C}\right)[30,31]$ could also be obtained in RTILs in milder conditions. It could also lead to different electrodeposition mechanisms and stripping processes as reported by Compton et al. [18] when the anion of the RTIL varied. Furthermore, one of the specific properties of RTILs is their relatively high viscosity since it may have important drawbacks especially in electrochemistry. Viscosity greatly influences the diffusion of metal ions and conductivity of the salts. The size, the shape and the molar mass of the anion are also known to contribute to the viscosity of RTILs and it was reported that the more viscous RTILs were observed for RTILs having the smaller, lighter, and more symmetric anions [1, 32, 33]. It was also reported [1] that other parameters could have significant effects on the viscosity, notably the relative basicity of the anions, their ability to form hydrogen bonds or to allow van der Waals attractions $[34,35]$. Higher viscosities of RTILs can also be observed depending on the nature of the cation types as the increase of the length of alkyl substituents leads to stronger van der Waals interactions between larger cations [32, 34, 36-38]. Finally, the nature of the anion also influences significantly the viscosity of the ionic liquid, notably through their ability to participate in hydrogen bonding.

Aqueous electrolytes exhibit usually higher conductivity due to proton-hopping mechanism and also lower viscosity. The viscosity is the most decisive factor for the conductivity of RTILs as a simple inversely proportional relationship between the molar conductivities and viscosities of RTILs called Walden's law is observed.

Several RTILs have already been investigated for the electrodeposition of tin on an inert substrate such as Pt or glassy carbon, i.e. substrates avoiding the formation of alloys. Sn(II)/Sn and $\mathrm{Sn}(\mathrm{IV}) / \mathrm{Sn}(\mathrm{II})$ redox couples have also been investigated by cyclic voltammetry on different electrodes in aluminum chloride-1-ethyl-3-methylimidazolium chloride (denoted $\mathrm{AlCl}_{3}$-EMICl) at $40^{\circ} \mathrm{C}$ [23]. They showed that the electrodeposition process of tin deposition depended on the nature of the substrate and that the reduction process of $\mathrm{Sn}$ (II) on Pt electrode gave rise to the electrodeposition of $\mathrm{Sn}$ metal. The corresponding diffusion coefficient was in the order of magnitude of about $10^{-7} \mathrm{~cm}^{2} \mathrm{~s}^{-1}$. These authors also showed that the oxidation of $\mathrm{Sn}$ (II) to $\mathrm{Sn}$ (IV) was hindered in the voltammogram by the weak adsorption of $\mathrm{Sn}$ (II). Similar results were obtained in zinc chloride-1-ethyl-3-methylimidazolium chloride (denoted $\mathrm{ZnCl}_{2}$-EMICl) [29]. However, haloaluminate-anion-based ionic liquids are very sensitive to water and air, their uses for industrial applications are restricted. Less reactive anions were explored such as tetrafluoroborate $\left(\mathrm{BF}_{4}^{-}\right)$, hexafluorophosphate $\left(\mathrm{PF}_{6}^{-}\right)$, dicyanamide $\left(\mathrm{DCA}^{-}\right)$, bis (trifluoromethylsulfonyl) imide ( $\left.\mathrm{NTf}_{2}{ }^{-}\right)$and so on. For example, Yang et al. [26] studied the electrodeposition of tin from $\mathrm{Sn}(\mathrm{II})$ in the $\mathrm{EMIBF}_{4}$ and showed that the reduction of $\mathrm{Sn}(\mathrm{II})$ on Pt electrode was electrochemically irreversible. Morimitsu et al. [6] studied the electrochemistry of $\mathrm{Sn}$ (II) in 1-ethyl-3-methylimidazolium tetrafluoroborate containing free chloride ions $\left(\mathrm{EMI}_{-} \mathrm{BF}_{4}-\mathrm{Cl}\right)$ originated from the mixture of $\mathrm{EMICl}$ and $\mathrm{NaBF}_{4}$. The authors showed that the electrodeposition of tin proceeded through a quasi-reversible step with two electron transfers. Nevertheless, $\mathrm{BF}_{4}^{-}$and $\mathrm{PF}_{6}^{-}$-based ionic liquids are considered as undesirable due to the formation of corrosive HF in presence of water. Katayama et al. [10] investigated the electrochemical reduction of $\mathrm{Sn}$ (II) with $\mathrm{Pt}$ electrode in 1-butyl-1methylpyrrolidinium bis (trifluoromethylsulfonyl) imide $\left(\mathrm{BMP}-\mathrm{NTf}_{2}\right)$ at $25^{\circ} \mathrm{C}$. They introduced $\mathrm{Sn}$ (II) by the anodic dissolution of $\mathrm{Sn}$ and found that the current efficiency relative to the 
electrodeposition of $\mathrm{Sn}$ was close to $100 \%$. The voltammeric oxidation of $\mathrm{Sn}$ (II) to $\mathrm{Sn}$ (IV) was not observed due to the limitation of the explored potential window. In addition, the electrodeposition of $\mathrm{Sn}$ on a reactive substrate as copper was achieved in BMP-NTf 2 containing $\mathrm{Sn}$ (II) [38] and should give rise to $\mathrm{Cu}-\mathrm{Sn}$ alloys. Sun et al. [38] studied the electrochemical reaction of $\mathrm{Sn}$ (II) in 1-ethyl-3-methylimidazolium dicyanamide (EMI-DCA) on Pt electrode at $40^{\circ} \mathrm{C}$. Sn deposits produced by potentiostatic electrolysis on $\mathrm{Cu}$ substrate showed various morphologies depending on the deposition potentials.

Although $\mathrm{DCA}^{-}$and $\mathrm{NTf}_{2}{ }^{-}$- based ionic liquids are considered as ones of the most promising electrolytes for the electrodeposition of metal, only few information is available in the literature to compare their specific properties for instance using 1-ethyl-3-methylimidazolium cation. Therefore, this paper is devoted to study the electrochemical behavior of $\mathrm{Sn}$ in three different RTILs: 1-ethyl-3-methylimidazolium dicyanamide (EMI-DCA), 1-butyl-1-methylpyrrolidi nium bis (trifluoromethanesulfonyl) imide $\left(\mathrm{BMP}^{\left.-\mathrm{NTf}_{2}\right)}\right.$ and 1-ethyl-3-methylimidazolium bis-

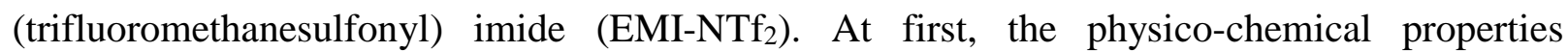
(viscosity, conductivity and density) of the RTILs were investigated. Then, the electrochemical deposition mechanisms of $\mathrm{Sn}$ were presented and the influence of the nature of the anion/cation of the RTILs on the deposition process was discussed. Finally, $\mathrm{Cu}-\mathrm{Sn}$ alloys were prepared by reduction of $\mathrm{Sn}$ (II) ions using a reactive $\mathrm{Cu}$ working electrode. The deposits were characterized by XRD and SEM, and the composition of the alloys was obtained by EDS analyses.

\section{EXPERIMENTAL SECTION}

EMI-DCA ( $\geq 98.5 \%)$, BMP-NTf $_{2}(99.9 \%)$ and EMI-NTf 2 (99.5\%) were purchased from Fluka and Solvionic and stored in a glove box filled by argon (water content $\leq 5 \mathrm{ppm}$ ). The water content was estimated from Karl-Fischer measurements and was found to be: $1066 \mathrm{ppm}$ for

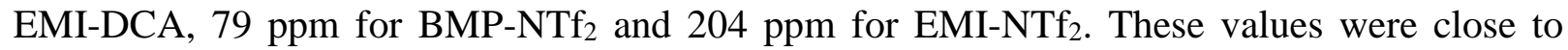
those announced by suppliers (5000 ppm, 2 ppm and 500 ppm, respectively).

The density of RTILs were measured using an Anton Paar DSA-5000 digital densimeter at atmospheric pressure with experimental uncertainty less than $\pm 4 \times 10^{-5} \mathrm{~g} \cdot \mathrm{cm}^{-3}$. Dynamic viscosities of RTILs were determined with an Anton Paar Automated Micro Viscometer (AMVn). The automated micro viscometer is based on the rolling ball principle. The sample to be measured is introduced into a glass capillary in which a steel ball rolls. The viscosity of the tested fluid can be determined by measuring the rolling time of the steel ball. A built-in Pt100 thermometer measures and controls the exact temperature. The experimental uncertainty was lower than $\pm 2 \mathrm{mPa}$ s for viscosity range in between 300 to $700 \mathrm{mPa} \mathrm{s}$ and $\pm 0.3 \mathrm{mPa}$ for viscosities values lower than $300 \mathrm{mPa}$.

All the experiments including the electrolyte preparation and handling were performed in the glove box filled by Ar using a three electrodes cell. A Pt disk electrode $\left(\mathrm{S}_{\mathrm{Pt}}=0.03 \mathrm{~cm}^{2}\right)$ was used as inert working electrode to avoid the formation of any Sn-based alloys during the electroreduction step for the study of the electrochemical behaviors of $\mathrm{Sn}(\mathrm{II}) / \mathrm{Sn}$. Before each experiment, the Pt working electrode was mechanically polished, the last step being performed 
in an aqueous alumina suspension $(0.05 \mu \mathrm{m})$ to obtain a mirror-like surface. Then the electrodes were rinsed with distilled water to remove traces of alumina using an ultrasonic treatment. Finally the samples were dried under vacuum at around $120^{\circ} \mathrm{C}$ before introduction in the glove box.

\section{Insert Fig. 1}

The counter electrode was a Sn bar prepared by fusing Sn powder (prolabo, purety 99.97\%) and then cooling the fused tin in a molder to obtain a bar. Well-known tin contents were introduced in the electrolyte by anodic dissolution of the prepared Sn bar electrodes using a two-compartment cell presented in Fig. 1. To succeed, a tin bar used as working electrode was placed in the first compartment. The counter electrode was also a Sn bar placed in the second compartment separated from the first compartment with a G4 glass frit to avoid any pollution of the Sn(II)-containing solution. All the electrochemical experiments were carried out using a Biologic VMP3 potentiotat/galvanostat.

Finally, the electrodeposition experiments were carried out on $1 \mathrm{~cm} \times 1 \mathrm{~cm} \mathrm{Mo} \mathrm{or} \mathrm{Cu}$ foils and characterized by the techniques as follows: XRD patterns were collected using a Rigaku Ultima IV diffractometer and SEM images were obtained by a Jeol JEM 100 CX II scanning electron microscope equipped with a Jeol high resolution scanning attachment (SEM-FEG).

\section{RESULTS}

\section{III.1. Physico-chemical properties of RTILs}

Before studying the electrochemical behaviors of $\mathrm{Sn}(\mathrm{II}) / \mathrm{Sn}$ on inert substrate, the main characteristics of the RTILs used in this study, such as viscosity and conductivity were measured depending on the nature of the RTIL and the temperature of the electrolyte between 25 and $100^{\circ} \mathrm{C}$ which corresponded to the temperature range used in the electrochemical section for the deposition of Sn and Sn-alloys. Data collected at $25^{\circ} \mathrm{C}$ are for instance summarized in Table 1.

\section{Insert Table 1}

The RTILs were selected in order to study both the influence of the anion (DCA $\mathrm{Dr}^{-} \mathrm{NTf}_{2}^{-}$) and the cation $\left(\mathrm{EMI}^{+}\right.$or $\left.\mathrm{BMP}^{+}\right)$on the electrodeposition mechanism. Whatever was the RTIL, values obtained were in the same order of magnitude of those reported in the literature $[39,40]$. The influence of the temperature on the density of the RTIL is presented in Fig. 2. The variation of $\rho v s$. T is evidenced but this variation is small. The decomposition temperature of these three RTILs was higher than $360^{\circ} \mathrm{C}$ [34], giving rise to a large temperature window for the preparation of the tin-based materials.

\section{Insert Fig. 2}

The temperature dependences of the conductivities and viscosities of three RTILs from $25^{\circ} \mathrm{C}$ to $100^{\circ} \mathrm{C}$ are given in Figs. $3 \mathrm{a}$ and $3 \mathrm{~b}$. 


\section{Insert Fig. 3a \& 3b}

As shown in these figures, significant decrease of viscosity was observed with increasing temperature. Whatever was the RTIL, the variation of the viscosity $v s$. 1/T obeys the Arrhenius' law and the data allowed calculating the activation energy, $\mathrm{E}_{\mathrm{a}}$, for viscous flow. It was found that the viscosity of BMP-NTf $2(76.6 \mathrm{mPa} \mathrm{s})$ measured at $25^{\circ} \mathrm{C}$ was larger than that of EMI-NTf $2(33.3 \mathrm{mPa}$ s) or EMI-DCA $(14.7 \mathrm{mPa} \mathrm{s})$. Consequently, this should have a great influence on the electrodeposition process since the diffusion coefficient is related to the viscosity. Therefore, the diffusion coefficient of tin species in BMP-NTf 2 should be the smallest among the three RTILs.

According to the basic studies on viscosity of non-haloaluminate ionic liquids with the same anion, reported in the literature [41, 42], the viscosities of the ionic liquids composed of the imidazolium cation are relatively low, and the larger the alkyl substituent on the imidazolium cation is, the more viscous the fluids tend to be. It is also well known that the viscosity is related to the nature of anions. Moreover, the size, the shape and the molar mass of the anion contribute to the viscosity. Thus, RTIL with the smaller, lighter and more symmetric anions leads to more viscous electrolyte. For ionic liquids with the same cation, the lowest viscosity was observed for the one having the large $\mathrm{NTf}_{2}^{-}$anions, according to the literature [43]. However, it can be added that, in the case of $\mathrm{DCA}^{-}$ionic liquids, the viscosity is about two times lower. It is probably because the delocalized charge weakens the ion-ion interactions in these ionic liquids.

Finally, it is worth to mention that the viscosity is not only dependent on both the nature of the cations and anions, but also on the presence of impurities, especially water. This explains why the interpretation of data reported in literature is not always consistent.

\section{III.2. Determination of the electroactive domains}

Before studying the $\mathrm{Sn}(\mathrm{II}) / \mathrm{Sn}$ redox couple in RTILs, the electroactive domains of the three RTILs were investigated at room temperature with a Pt electrode $\left(0.03 \mathrm{~cm}^{2}\right)$ by cyclic voltammetry $(\mathrm{v}=50 \mathrm{mV} / \mathrm{s})$ without the presence of tin ions in solution. This provided blank curves which allowed the determination of the electroactive domains (Fig. 4).

\section{$\underline{\text { Insert Fig. } 4}$}

Whatever was the RTIL, the curves (Fig. 4) recorded in a wide potential range (about $3 \mathrm{~V}$ ) did not reveal any significant currents (of the order of $100 \mathrm{nA}$ ), indicating a very good electrochemical stability of the selected RTILs and the absence of high content of impurities. Neither oxidation nor reduction peak was pointed out, indicating the absence of electroactive impurities, i.e. no side reactions were detected during the anodic and the cathodic scans. 
The electrolyte resistances measured at $25^{\circ} \mathrm{C}$ by impedance measurements were equal to $80 \Omega$ for EMI-DCA, $680 \Omega$ for BMP-NTf 2 and $270 \Omega$ for EMI-NTf 2 .

\section{III.3. Preparation of the Sn-containing solution}

Because of the too low solubility of chlorinated tin salts in RTILs, and in regards to the hydrated state of the available salts, tin was introduced in the RTIL by anodisation of Sn electrode. The benefits of the anodic dissolution were a better control of the Sn(II) content in the solution and the absence of water or other anions which usually lead to un-controlled complexation state of the ionic species.

In the case of EMI-DCA, Sn(II) ions were introduced into the solution by anodic dissolution of a Sn bar in galvanostatic mode using the two compartments cell described previously (Fig. 1). A constant current was applied to the Sn electrode and the $\mathrm{Sn}$ (II) content in solution obviously increased with time according to Faraday's law (1):

$\mathrm{Q}=\mathrm{I} \times \mathrm{t}=\frac{\Delta \mathrm{m}_{\mathrm{Sn}}}{\mathrm{M}_{\mathrm{Sn}}} \times \mathrm{n}_{\mathrm{e}} \times \mathrm{F}$

with I, the current applied to the electrode, $t$, the duration of the galvanostatic pulse, $\mathrm{M}_{\mathrm{Sn}}$, the molar mass of tin, $\Delta \mathrm{m}_{\mathrm{Sn}}$, the weight loss of the tin electrode, $\mathrm{n}_{\mathrm{e}}$ the number of electron exchanged in the reaction, and $\mathrm{F}$, the Faraday constant. In a first approximation, we considered that the yield of the reaction $\mathrm{Sn} \rightarrow \mathrm{Sn}(\mathrm{II})+2 \mathrm{e}^{-}$was almost $100 \%$.

In the case of EMI-NTf $f_{2}$ and $\mathrm{BMP}_{\mathrm{NTf}}$, potentiostatic anodisation was preferred due to the too high resistivity of the solutions. A constant dissolution potential of $+0.5 \mathrm{~V} v s$. Pt was applied to the tin working electrode. The electrolysis was stopped after reaching the required $\mathrm{Sn}$ (II) content. Whatever was the RTIL, the number of electrons also deduced from the Faraday's law was found to be $1.99 \pm 0.01$, indicating that the anodic reaction leads to the formation of divalent $\mathrm{Sn}(\mathrm{II})$ as described above.

\section{III.4. Determination of the standard potential of the $S n(I I) / S n$ redox couple in RTILs}

At first, the evolution of the free potential for different $\mathrm{Sn}$ (II) contents for the three RTILs was studied. The first measurement was done with the highest concentrated solution and the next ones after dilution. As expected according to the Nernst's Equation, a linear variation of the free potential vs. $\log$ [Sn(II)] was observed whatever was the RTIL (Fig. 5) containing Sn(II) initial concentration of $0.1 \mathrm{~mol} \mathrm{~L}^{-1}$. The slopes of the curves recorded at $25^{\circ} \mathrm{C}$ lead to the number of exchanged electrons. Whatever was the RTIL, the experimental values were $1.97 \pm$ 0.05 , very close from the theoretical value $(n=2)$. The extrapolation to the origin of the curves

leads to the value of the standard potential. It was found that $E_{S n(I I) / S n}^{0}$ is : $-0.54 \pm 0.01 \mathrm{~V}$ in 
EMI-NTf $_{2},-0.53 \pm 0.01 \mathrm{~V}$ in BMP-NTf 2 , and $-1.43 \pm 0.01 \mathrm{~V}$ in EMI-DCA. These values clearly showed the influence of the RTIL on the standard potential of the $\mathrm{Sn}(\mathrm{II}) / \mathrm{Sn}$ redox couple.

\section{Insert Fig. 5.}

In particular, these data revealed a strong influence of the nature of the anions $\left(\mathrm{NTf}_{2}{ }^{-}\right.$or $\left.\mathrm{DCA}^{-}\right)$ on $\mathrm{E}^{0}$. This influence was probably due to the donor ability of the anions. Gutmann showed that the potential of $\mathrm{M}^{\mathrm{n}+} / \mathrm{M}$ tended to be more negative with an increase in the donor property of solvent [44]. According to the order of the donor ability of the anions $\mathrm{DCA}^{-}>\mathrm{Cl}^{-}>\mathrm{NTf}_{2}{ }^{-}$ $[45,46]$, the standard potential of $\mathrm{Sn}(\mathrm{II}) / \mathrm{Sn}$ in EMI-DCA was much more negative than that in both ionic liquids with the anion $\mathrm{NTf}_{2}$.

\section{III.5. Study of tin redox system by cyclic voltammetry}

A typical voltammogram recorded between -0.8 and $+0.5 \mathrm{~V} \mathrm{vs} . \mathrm{Pt}(\mathrm{v}=50 \mathrm{mV} / \mathrm{s})$ with a nonreactive Pt electrode in EMI-NTf 2 containing $0.01 \mathrm{~mol} \mathrm{~L}^{-1} \mathrm{Sn}$ (II) ions at $25^{\circ} \mathrm{C}$ is given in Fig. 6a. Potentials were scanned from the equilibrium to the cathodic side until $-0.8 \mathrm{~V} v s$. Pt and then to $+0.5 \mathrm{~V} v s$. Pt in the oxidation side.

\section{Insert Fig. 6a.}

A cathodic peak was observed at around $-0.30 \mathrm{~V} v s$. Pt due to the reduction of $\mathrm{Sn}$ (II) to $\mathrm{Sn}$. This peak was associated to the anodic peak observed during the reverse scan at around $-0.07 \mathrm{~V}$ vs. Pt which corresponded to the oxidation of Sn formed during the cathodic scan. The shape of the reduction and oxidation peaks were characteristic of the deposition of an insoluble metal ( $\mathrm{Sn}$ in the present case) and its dissolution during the reverse scan, respectively.

As shown in the inset of Fig. 6a, the anodic stripping overtook the cathodic deposition at $-0.22 \mathrm{~V}$. Thus, the current crossed to the anodic side and the overpotential is related to nucleation and growth process. The latter was needed before bulk deposition of Sn. In other words, the reduction potential of $\mathrm{Sn}$ (II) ions is more negative than expected due to this electrocrystallisation overpotential. Obviously, an increase of the scan rate should have a great influence on the potential of a diffusion controlled process such as the reduction of $\mathrm{Sn}$ (II). The cyclic voltammograms obtained for increasing scan rates are presented in Fig. 6b. As expected, the oxidation peak was unchanged whatever was the scan rate; in contrast the overpotential due to electro-crystallization phenomenon during the reduction step increased with the scan rate (i.e. the reduction peak was observed at more negative potential)

One may notice that the oxidation of $\mathrm{Sn}$ (II) to $\mathrm{Sn}(\mathrm{IV})$ was not observed in the explored potential window.

\section{Insert Fig. 6b.}


The difference in potential (Fig. 6a) between the anodic and the cathodic peaks, denoted $\Delta \mathrm{E}_{\mathrm{a}-\mathrm{c}}$ henceforth, was different depending on the RTIL but no obvious correlation could be pointed out between the variation of $\Delta \mathrm{E}_{\mathrm{a}-\mathrm{c}}$ and the parameters given in Table 2. Moreover, due to the overpotential electro-crystallization, it was difficult to compare and to interpret the variation of $\Delta \mathrm{E}_{\mathrm{a}-\mathrm{c}}$ in terms of reversibility or irreversibility of the reaction. The influence of the ohmic drop was also an important factor which has to be taken into account for a good interpretation of our results. The studies carried out on this subject will be published in a next coming paper.

\section{Insert Table 2}

The same curve shape was observed in BMP-NTf $f_{2}$ in presence of $\mathrm{Sn}(\mathrm{II})$ involving a nucleation and growth process. In that case, the difference in potential, $\Delta \mathrm{E}_{\mathrm{a}-\mathrm{c}}$ was higher than that observed in EMI-NTf 2 and was about $350 \mathrm{mV}$.

\section{Insert Fig. 7}

As shown in Fig. 7, if the reduction scan was stopped and maintained at $-0.9 \mathrm{~V} v s$. Pt for a few seconds (from 0 to $10 \mathrm{~s}$ with a potential step of $2 \mathrm{~s}$ ), the intensity of the oxidation peak related to Sn dissolution increased with increasing potential stop time. It means that during the potential stop, Sn accumulated onto the electrode, giving rise to higher oxidation peak intensity. The variation of the capacity, $\mathrm{Q}_{\mathrm{a}}$, deduced from the area under the oxidation peak vs. the duration of the stop is given in Fig. 8. A linear variation of $\mathrm{Q}_{\mathrm{a}} v s$. $\mathrm{t}$ was obtained and the slope of the curve gives rise to the deposition rate of $\mathrm{Sn}$ in this electrolyte. In the present case, the slope was $2.6 \times 10^{-6} \mathrm{C} / \mathrm{s}$, i.e. the deposition rate was $1.6 \times 10^{-6} \mathrm{mg} / \mathrm{s}$ in our experimental conditions.

\section{Insert Fig. 8.}

\section{III-6. Determination of the diffusion coefficient of Sn(II)}

Reaction rates are usually related to the mass transportation of chemical species. This is more pronounced in ionic liquids due to their specific viscosity compared to aqueous solutions. Moreover, the charge on the electroactive species ( $\mathrm{Sn}$ (II) in the present case) must also be considered due to strong interaction between the charged species and the constituted ions of the ionic liquids. The shape of the curves with a sharp decrease of the current is a feature of solid deposition. This decrease in our case occurred at around - $0.23 \mathrm{~V}$ with the compensation of IR drop. Thus, small diffusion coefficient should be preferable to obtain smooth and homogeneous Sn deposits. 
The diffusion coefficient of $\mathrm{Sn}(\mathrm{II})$ ions, denoted $\mathrm{D}_{\mathrm{Sn}(\mathrm{II})}$ hereafter, was determined from hydrodynamic voltammetry, i.e. using a Pt rotating disk electrode (RDE). With such a system, the current related to mass transfer tended to a limit value denoted $\mathrm{I}_{\mathrm{L}}$, i.e. a current plateau was reached after a few minutes. The variation of the limited current $I_{L} v s$. $\omega$, the rotating speed, gave rise to the number of exchanged electrons. A straight line should be observed when the electron transfer reaction is reversible. Typical hydrodynamic voltamogramms recorded (scan rate: $\left.\mathrm{v}=5 \mathrm{mV} \mathrm{s}^{-1}\right)$ on the cathodic side with a Pt working electrode $\left(0.03 \mathrm{~cm}^{2}\right)$ in $0.01 \mathrm{M} \mathrm{Sn}$ (II) in EMI-NTf $f_{2}$ for increasing $\omega$ values are given in Fig. 9. In these steady-state I-E curves, the potential values were IR-drop compensated.

\section{Insert Fig. 9.}

Whatever was the RTIL, the curves exhibited well-defined plateau for each $\omega$ value, i.e. the current tended to a constant $I_{L}$ value. In addition, in the case of a semi-infinite diffusion, the relationship of the limiting current $v s$. the square root of the electrode rotation rate obeyed the Levich's equation:

$$
I_{L}=-0.62 n_{e} F S D_{S n(I I)}^{2 / 3} v^{-1 / 6} C_{\mathrm{Sn}(\mathrm{II})} \omega^{1 / 2}
$$

with $\mathrm{S}$, the surface of the Pt working rotating disk electrode $\left(0.03 \mathrm{~cm}^{2}\right), \mathrm{D}_{\mathrm{Sn} \text { (II) }}$ the diffusion coefficient of $\mathrm{Sn}(\mathrm{II}), v$, the kinematic viscosity $\left(0.219 \mathrm{~cm}^{2} / \mathrm{s}\right), \mathrm{C}_{\mathrm{Sn} \text { (II) }}$ the concentration of $\mathrm{Sn}(\mathrm{II})$ ions and $\omega$, the rotating electrode speed.

The shape of the I-E curves provided also interesting information on the mechanism involved during the cathodic step. Indeed, the vertical decrease of the current at around $-0.25 \mathrm{~V} v s$. $\mathrm{Pt}$ seemed to be an indication of the good reversibility of the $\mathrm{Sn} \leftrightarrow \mathrm{Sn}(\mathrm{II})+2 \mathrm{e}^{-}$reaction. To verify this assumption, we determined the number of electron exchanged in the reaction, $\mathrm{n}_{\mathrm{e}}$, from the classical relation used in the case of a RDE in the case of the presence of a soluble and an insoluble species. Indeed, one had: $\mathrm{E}_{3 / 4}-\mathrm{E}_{1 / 4}=0.029 / \mathrm{n}$ at $25^{\circ} \mathrm{C}$ where $\mathrm{E}_{1 / 4}$ and $\mathrm{E}_{3 / 4}$ were the potential observed at $\mathrm{I}_{\mathrm{L}} / 4$ and $3 \times \mathrm{I}_{\mathrm{L}} / 4$, respectively. An expanded view for $\omega=4000 \mathrm{tr} \mathrm{min}^{-1}$ is given in the inset of Fig. 9. It was found that $\mathrm{E}_{3 / 4}-\mathrm{E}_{1 / 4}=0.014 \pm 0.001 \mathrm{~V}$, i.e. the number of electron exchanged in the reaction was about 2 which is very close to the theoretical value and to that given above. Moreover, as expected from relation (2), a linear variation of $\mathrm{I}_{\mathrm{L}}=f\left(\omega^{1 / 2}\right)$ was observed (Fig. 10), meaning the reduction of Sn(II) was controlled by the mass transport. An increase of $I_{L}$ with increasing $\omega$ values was observed (Fig. 10), i.e. the kinetics rate became faster and faster. In other words, the higher the $\omega$ values were, the higher the concentration of electroactive species at the electrode/electrolyte interface was, and the faster the kinetics was. Since the value $n_{e}$ was confirmed, it was possible to determine the diffusion coefficient $D_{S n(I)}$ from the slope of the curve. 


\section{Insert Fig. 10.}

The values of the diffusion coefficient of $\mathrm{Sn}$ (II) deduced from the slope of the curve $\mathrm{I}_{\mathrm{L}}=f\left(\omega^{1 / 2}\right)$ with the three RTILs are reported in Table 2. These values confirmed that the higher the

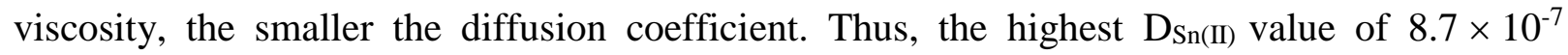
$\mathrm{cm}^{2} \mathrm{~s}^{-1}$ was obtained in EMI-DCA which has the lowest viscosity $(\mu=14.7 \mathrm{mPa}$ s). On the opposite side, the lowest $\mathrm{D}_{\mathrm{Sn}(\mathrm{II})}$ value was observed in BMP-NTf 2 having the highest viscosity.

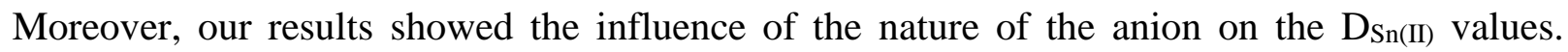
From Table 2, we found a good correlation of the diffusion coefficient $\mathrm{D}_{\mathrm{Sn}(\mathrm{II})}$ with the viscosity of the ionic liquids which contains the same anion $\mathrm{NTf}_{2}{ }^{-}$. $\mathrm{D}_{\mathrm{Sn}(\mathrm{II})}$ being inversely proportional to the viscosity, $\mathrm{D}_{\mathrm{Sn}(\mathrm{II})}$ in EMI-NTf ${ }_{2}$ was two times bigger than that in BMP-NTf $\mathrm{E}_{2}$ with a twice smaller viscosity. Even if the viscosity of EMI-DCA is twice smaller than that of EMI-NTf 2 , the $D_{S n(I I)}$ value obtained in EMI-DCA was almost five times higher than the one obtained in EMI-NTf 2 . The $\mathrm{D}_{\mathrm{Sn}(\mathrm{II})}$ depended mainly on the viscosity of ionic liquid. In fact, according to the

Stokes-Einstein equation $D=\frac{R T}{6 \pi N_{A} \eta r}$, the hydrodynamic radius of the $\mathrm{Sn}$ (II) in the ionic

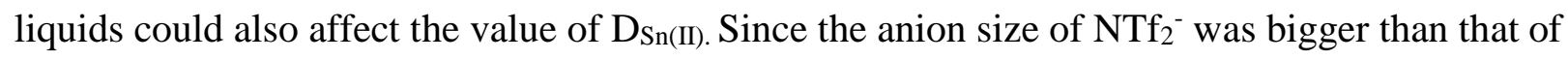
$\mathrm{DCA}^{-}$, the hydrodynamic radius of $\mathrm{Sn}$ (II) with $\mathrm{NTf}_{2}{ }^{-}$should be bigger than that of $\mathrm{Sn}$ (II) with $\mathrm{DCA}^{-}$. Consequently, it was reasonable to get a $\mathrm{D}_{\mathrm{Sn}(\mathrm{II})}$ in EMI-DCA almost five times bigger

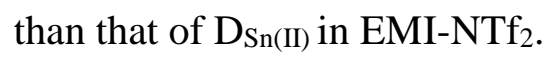

Then, the effect of the temperature of the RTILs on the kinetics rate was investigated. The diffusion coefficients $\mathrm{D}_{\mathrm{Sn}(\mathrm{II})}$ determined in the RTILs with $0.01 \mathrm{M} \mathrm{Sn}$ (II) at different temperatures are presented hereafter (Table 3). For instance, in EMI-NTf 2 , a rapid decrease of the resistance of the electrolyte with increasing temperature was pointed out: $270 \Omega$ at $25^{\circ} \mathrm{C}$ and $115 \Omega$ at $100^{\circ} \mathrm{C}$. The conductivity increases (i.e. the resistance decreases) with temperature, because higher temperature results in the decrease of viscosity which improves the mobility of ions. Cyclic voltammograms were carried out at various temperatures (Fig. 11). Thus, the discrepancy of the electrolyte resistance and the increase of $\mathrm{D}_{\mathrm{Sn}(\mathrm{II})}$ occurred with increasing temperature. As expected, the diffusion coefficient $\mathrm{D}_{\mathrm{Sn}(\mathrm{II})}$ increases with temperature from $1.9 \times$ $10^{-7} \mathrm{~cm}^{2} \mathrm{~s}^{-1}$ at $25^{\circ} \mathrm{C}$ to $5.2 \times 10^{-7} \mathrm{~cm}^{2} \mathrm{~s}^{-1}$ at $100^{\circ} \mathrm{C}$ in the case of EMI-NTf 2 containing $0.01 \mathrm{M}$ $\mathrm{Sn}$ (II) electroactive species. However, this coefficient did not seem to be strongly influenced by the variation of the temperature.

\section{Insert Table 3 and figure 11.}

The variation of $\ln \left(\mathrm{D}_{\mathrm{Sn}(\mathrm{II})}\right)$ vs. the reverse of the absolute temperature given in Fig. 12 obeyed the Arrhenius' law: $D_{\text {Sn(II) }}=D_{o} \exp \left(-E_{a} / R T\right)$. As shown in this figure, a linear variation of $\ln$ ( $\left.\mathrm{D}_{\mathrm{Sn}(\mathrm{II})}\right)$ vs. 1/T ( $\mathrm{T}$ expressed in $\mathrm{K}$ ) was observed. It was found that $\mathrm{E}_{\mathrm{a}}=11.6 \mathrm{~kJ} \mathrm{~mol}^{-1}$ and $\mathrm{D}_{0}=2.17 \times 10^{-5} \mathrm{~cm}^{2} \mathrm{~s}^{-1}$ for EMI-NTF 2 and $\mathrm{E}_{\mathrm{a}}=7.6 \mathrm{~kJ} \mathrm{~mol}^{-1}$ and $\mathrm{D}_{\mathrm{o}}=0.15 \times 10^{-5} \mathrm{~cm}^{2} \mathrm{~s}^{-1}$ for BMP-NTF $2 . \mathrm{D}_{0}$ and $\mathrm{E}_{\mathrm{a}}$ values were given in Table 4.

\section{$\underline{\text { Insert Fig. } 12 \text { \& Table } 4}$}

\section{III.7. Electrochemical deposition of Sn, $\mathrm{Cu}$ and $\mathrm{Cu}-\mathrm{Sn}$ alloys}




\section{III.7.1 Electrodeposition of Sn onto an inert Mo substrate}

Tin was deposited by electro-reduction of $\mathrm{Sn}$ (II) ions onto a non-reactive molybdenum substrate. The SEM images obtained for a deposit at $25^{\circ} \mathrm{C}$ under over-potential conditions by applying a constant potential just before the occurrence of the reduction peak in the cyclic voltammogram of Fig. 6a are given in Fig. 13. SEM images revealed clear differences depending on the nature of the RTILs. The most adhesive, dense and homogeneous electrodeposit film was obtained in EMI-NTf 2 containing $\mathrm{Sn}$ (II) (Fig. 13-C1 and 13-C2). Indeed, the films prepared in EMI-DCA and BMP-NTf 2 were not homogeneous and did not cover all the surface; thus, large cavities were clearly evidenced. In EMI-DCA and BMP-NTf $f_{2}$, large particles of 1-2 $\mu \mathrm{m}$ were observed (Fig. 13-B2). In contrast, the films prepared in EMI$\mathrm{NTf}_{2}$ were more homogeneous and composed of smaller particles (about $200 \mathrm{~nm}$ ). Note that in EMI-DCA, the structure of the deposited tin was macroporous with the presence of some tin nanowires (Fig. 13-B2).

\section{Insert Fig. 13.}

The XRD patterns corresponding to the three deposited films given in Fig. 13 are presented in Fig. 14. Whatever was the electrolyte used for the preparation of the films, the XRD patterns revealed only the presence of $\mathrm{Sn}$ in addition with those relative to Mo substrate.

\section{Insert Fig. 14.}

From these results, we decided to focus our attention on the compounds prepared in EMI-NTf 2 with $0.01 \mathrm{~mol} \mathrm{~L}^{-1} \mathrm{Sn}(\mathrm{II})$ henceforth.

\section{III-7.2. Electrodeposition of Sn onto a reactive Cu substrate}

The behavior of copper as reactive working electrode was investigated by cyclic voltammetry in EMI-NTf 2 containing $0.02 \mathrm{M} \mathrm{Cu}(\mathrm{I})$ at $25^{\circ} \mathrm{C}$ (scan rate: $50 \mathrm{mV} / \mathrm{s}$ ). The cyclic voltammogram recorded with a Pt working electrode $\left(0.03 \mathrm{~cm}^{2}\right)$ at $25^{\circ} \mathrm{C}$ is given in Fig. $15\left(\mathrm{v}=50 \mathrm{mV} \mathrm{s}^{-1}\right)$.

\section{Insert Fig. 15.}

Copper cations were introduced by anodic dissolution of a copper bar. It is well known that in ionic liquids $\mathrm{Cu}$ (II) are often unstable and dismutation reaction involving $\mathrm{Cu}$ (II) and $\mathrm{Cu}$ occurs according to: $\mathrm{Cu}(\mathrm{II})+\mathrm{Cu} \rightarrow 2 \mathrm{Cu}(\mathrm{I})[47,48]$. This could explain why the number of exchanged electrons deduced from the analysis of the curves using a rotating disk electrode as discussed above was found to be close to 1 . The well-defined waves observed in EMI-NTf 2 in presence of copper ions were attributed to the $\mathrm{Cu}(\mathrm{I}) / \mathrm{Cu}$ couple: the reduction peak observed at $-0.2 \mathrm{~V}$ vs $\mathrm{Pt}$ was related to the reduction of $\mathrm{Cu}(\mathrm{I}) \rightarrow \mathrm{Cu}$ whereas the oxidation peak detected at $+0.2 \mathrm{~V}$ vs $\mathrm{Pt}$ during the reverse scan was due to the re-oxidation of $\mathrm{Cu}$. 
The diffusion coefficient of $\mathrm{Cu}(\mathrm{I})$ ions, denoted $\mathrm{D}_{\mathrm{Cu}(\mathrm{I})}$, was also determined from hydrodynamic voltammetry, i.e. using a rotating disk electrode (RDE) in $0.02 \mathrm{M} \mathrm{Cu}(\mathrm{I})$ - EMI-NTf 2 for various rotating speed. It was found that $\mathrm{D}_{\mathrm{Cu}(\mathrm{I})}=2.48 \times 10^{-7} \mathrm{~cm}^{2} / \mathrm{s}$ at $25^{\circ} \mathrm{C}$. In the same conditions, $\mathrm{D}_{\mathrm{Sn}(\mathrm{II})}=1.9 \times 10^{-7} \mathrm{~cm}^{2} \mathrm{~s}^{-1}$ was previously obtained.

\section{III-7.3. Electrodeposition of $\mathrm{Cu}$-Sn alloys}

Let us consider now the formation of Sn-based alloys. As revealed from the binary phase diagram of $\mathrm{Cu}-\mathrm{Sn}[49]$ reproduced in Fig. $16, \varepsilon-\mathrm{Cu}_{3} \mathrm{Sn}$ and $\eta{ }^{\prime}-\mathrm{Cu}_{6} \mathrm{Sn}_{5}$ phases could be obtained at temperatures below $180^{\circ} \mathrm{C}$, depending on the operating conditions. The experimental enthalpies of formation of binary $\mathrm{Cu}-\mathrm{Sn}$ alloys $\left(\Delta_{\mathrm{f}} \mathrm{H}\right)$ were reported in the literature [50, 51]. The averages $\Delta_{\mathrm{f}} \mathrm{H}$ values reported at $298 \mathrm{~K}$ are the following: $-8.22 \pm 1 \mathrm{~kJ}^{\mathrm{mol}}{ }^{-1}$ for $\mathrm{Cu}_{3} \mathrm{Sn}(\varepsilon$

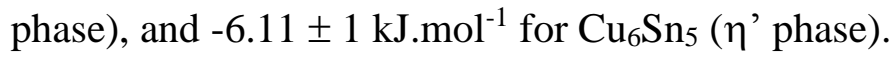

Potentiostatic electroformation of $\mathrm{Cu}-\mathrm{Sn}$ alloys was carried out in RTILs. According to the $\mathrm{Cu}-$ Sn phase diagram (Fig. 16), $\mathrm{CuSn}, \mathrm{Cu}_{3} \mathrm{Sn}$ or $\mathrm{Cu}_{6} \mathrm{Sn}_{5}$ could be obtained in our experimental conditions.

\section{Insert Fig. 16}

As reported in the literature, the redox couples potentials of two metals $M_{1}$ and $M_{2}$ with their respective $\mathrm{M}_{1}{ }^{\mathrm{n} 1+}$ and $\mathrm{M}_{2}{ }^{\mathrm{n} 2+}$ ions in solution are given by the Nernst's equation. In such conditions, there are three main electrochemical routes for the electrodeposition of $\mathrm{M}_{1}-\mathrm{M}_{2}$ alloys called method 1, 2 and 3, hereafter.

- Method 1: the first route consists in performing the reduction of $\mathrm{M}_{1}{ }^{1+}$ ions using a reactive electrode composed of $\mathrm{M}_{2}$ (i.e. reduction of $\mathrm{Sn}$ (II) on $\mathrm{Cu}$ in the present study).

- Method 2: this method is the most popular one and is based on the co-deposition of the two metals $\mathrm{M}_{1}$ and $\mathrm{M}_{2}$ from electroreduction of $\mathrm{M}_{1}{ }^{\mathrm{n} 1+}$ and $\mathrm{M}_{2}{ }^{\mathrm{n} 2+}$ ions ( $\mathrm{Sn}$ (II) and $\mathrm{Cu}(\mathrm{I})$ in the present case) onto an inert working electrode. It is important to note that if the standard potentials of the two redox couples are very different, the co-deposition of the two metals is somewhat difficult. However, one solution to overcome this problem is to reduce the potential difference between the first metal to the second one. Thus, according to the Nernst's law, the modification of the concentration allows reducing the potential difference between these two redox couples. Thus, $\mathrm{Cu}-\mathrm{Sn}$ alloys deposition can be favored if the concentration of the more noble metal (copper) is the lowest while keeping the second one (tin) constant. Thus, by adjusting the concentration ratio between $\mathrm{Cu}(\mathrm{I})$ and $\mathrm{Sn}(\mathrm{II})$, a shift of the reduction potential of copper towards the reduction potential of tin is expected, allowing the co-deposition of $\mathrm{Cu}$ and $\mathrm{Sn}$ and the formation of alloys.

- Method 3: to favor the formation of $\mathrm{Cu}-\mathrm{Sn}$ based alloys, a third method (method 3) was investigated in this study. It consisted in combining methods $1 \& 2$ described above. Thus, the 
electrodeposition of the Sn-based alloys was performed in EMI-NTf E $_{2}$ containing $\mathrm{Sn}$ (II) and $\mathrm{Cu}(\mathrm{I})$ ions with a concentration ratio of ions of $\mathrm{Cu}(\mathrm{I}) / \mathrm{Sn}(\mathrm{II})$ equals to $1 / 1$ or $1 / 10$. Finally, the working electrode was in copper to active the germination phenomena.

A first set of experiments (according to method 1) was performed using a $\mathrm{Cu}$ working electrode in presence of $0.01 \mathrm{~mol} \mathrm{~L}^{-1} \mathrm{Sn}(\mathrm{II})$ ions only in EMI-NTf 2 . For this series, the influence of the temperature of the electrolyte on the deposits was investigated. The SEM images and the corresponding XRD patterns are given in Fig. 17a and $17 \mathrm{~b}$, respectively. The lowest temperature led to the smallest particles size. Nevertheless, whatever was the temperature of the RTIL, the XRD patterns (Fig. 17b) did not exhibit any difference and all the diffraction lines were indexed with those of $\mathrm{Sn}$ in addition to those relative to the copper substrate.

\section{Insert Fig. 17a \& 17b}

Cross section images and EDX quantitative analysis of the deposit obtained at $25^{\circ} \mathrm{C}$ are presented in Fig. 17c. As shown here, the film electrodeposited at $25^{\circ} \mathrm{C}$ was very thin (less than $1 \mu \mathrm{m})$, rather compact but its homogeneity was doubtful even if a clear distinction between the $\mathrm{Cu}$ substrate and the electrodeposited $\mathrm{Sn}$ was observed. This observation was in good agreement with results deduced from XRD showing that the film prepared in such conditions was composed of $\mathrm{Sn}$ and that no trace of $\mathrm{Cu}-\mathrm{Sn}$ alloy could be detected.

\section{Insert Fig. 17c}

A second set of experiments was achieved according to the Method 3 that was described above. A positive influence of the concentration ratio $\mathrm{Cu}(\mathrm{I}) / \mathrm{Sn}$ (II) on the deposition potential of the $\mathrm{Cu}-\mathrm{Sn}$ alloys was expected. The alloys were prepared in potentiostatic mode in EMI-NTf $\mathrm{E}_{2}$ with $0.01 \mathrm{M}$ concentration for both $\mathrm{Sn}(\mathrm{II})$ and $\mathrm{Cu}(\mathrm{I})$, i.e. concentration ratio $[\mathrm{Cu}(\mathrm{I})] /[\mathrm{Sn}(\mathrm{II})]=1$. As discussed above, the formation of alloys for this concentration ratio should be difficult due to the huge potential difference between the two involved redox couples.

\section{Insert Fig. 18}

The XRD patterns of deposits obtained in EMI-NTf 2 in presence of $\mathrm{Sn}(\mathrm{II})$ and $\mathrm{Cu}(\mathrm{I})$ with a concentration ratio equal to 1 before and after heat-treatment are given in Fig. 18. As clearly shown in this figure, the deposit film was only composed of tin and did not evidence the presence of $\mathrm{Cu}-\mathrm{Sn}$ alloys. The effect of a post heat-treatment at moderate temperatures $\left(\leq 200^{\circ} \mathrm{C}\right)$ under vacuum was also investigated in order to study the influence of a moderate temperature on the crystallinity and the composition of the alloys but this did not show any positive effect on the crystallinity of the deposited film. Again, as discussed above, the potential difference was too high for generating alloys. In that case, the same experiments were performed in EMI-NTf 2 with a concentration ratio $[\mathrm{Cu}(\mathrm{I})] /[\mathrm{Sn}(\mathrm{II})]=1 / 10$

\section{Insert Fig. 19a}

The XRD obtained for example in potentiostatic mode with an applied potential of $-0.8 \mathrm{~V} v s$. $\mathrm{Ag}(\mathrm{I}) / \mathrm{Ag}$ considering the concentration ratio $[\mathrm{Cu}(\mathrm{I})] /[\mathrm{Sn}(\mathrm{II})]=1 / 10$ is given in Fig. 19a. All diffraction lines could be indexed based on the $\mathrm{Cu}_{3} \mathrm{Sn}$ phase (JCPDS card 65-4653- space 
group $\mathrm{P} 6 / \mathrm{mmm}$ ) in addition to those relative to $\mathrm{Cu}$ substrate. This composition was confirmed using energy dispersive $\mathrm{X}$-ray analysis.

The SEM image is given in Fig. 19b. The obtained alloys were composed of very small particles leading to a satisfactory coverage of the surface. The compactness and the homogeneity of the film were good without any trace of cracks. EDS quantitative analysis of the $\mathrm{Cu}-\mathrm{Sn}$ alloy cross section is presented in Fig 19c. The cross section image confirmed the homogeneity of the electrodeposited film. Moreover, a clear distinction between the $\mathrm{Cu}$ substrate and the electrodeposited $\mathrm{Cu}-\mathrm{Sn}$ alloy could be done. Quantitative analysis of $\mathrm{Cu}$ and Sn content within the film revealed a homogeneous distribution of each element within the film: the average content of $\mathrm{Sn}$ in the film was about 24 at\% (atomic percentage), in good accordance with results deduced from XRD. Finally, it must be noticed that the EDS spectrum clearly evidenced the presence of $\mathrm{Cu}_{3} \mathrm{Sn}$ in agreement with the XRD analysis.

\section{Insert Fig. 19b \&19c}

\section{Conclusions}

The electrochemical behaviors of $\mathrm{Sn}$ were studied in the EMI-NTf $f_{2}$ ionic liquid at room temperature. $\mathrm{Sn}$ (II) was introduced by the anodic dissolution of Sn with a current efficiency of nearly $100 \%$. The morphology of the Sn deposited from the EMI-NTf 2 , EMI-DCA and BMPN-Tf 2 were compared. The dense and homogenous Sn particles with size around $200 \mathrm{~nm}$ were only obtained from EMI-NTf 2 . The diffusion coefficient of $\mathrm{Sn}(\mathrm{II})$ in EMI-NTf 2 was found to be in the same order of magnitude as those reported for $\mathrm{Sn}(\mathrm{II})$ in BMP-NTf 2 and EMI-DCA. Furthermore, a dense and adherent $\mathrm{Cu}-\mathrm{Sn}$ alloy film could be obtained on the $\mathrm{Cu}$ substrate from EMI-NTf 2 by the electrochemical technique followed by thermal treatment. The composition of $\mathrm{Sn}-\mathrm{Cu}$ alloy was evidenced by XDR and EDS analysis and corresponded to $\mathrm{Cu}_{3} \mathrm{Sn}$ deposit. The $\mathrm{Sn}-\mathrm{Cu}$ film from $\mathrm{EMI}^{-\mathrm{NTf}_{2}}$ may be suitable to be used as anode material in lithium rechargeable batteries. 


\section{$\underline{\text { References }}$}

[1] P. Hapiot, C. Lagrost, Chem. Rev. 108 (2008) 2238-2264.

[2] H. Ohno, Electrochemical aspects of ionic liquids, H. Ohno, Ed., Wiley-Interscience (2009), ISBN-0-471-64851-5.

[3] L. E. Barrosse-Antle, A. M. Bond, R. G. Compton, A. M. O’ Mahony, R. I. Rogers, D. S. Silvester, Chem. Asian J. 5 (2010) 202-230.

[4] R. Hagiwara, K. Tamaki, K. Kubota, T. Goto, T. Nohira, J. Chem. Eng. Data 53 (2008) 355-358.

[5] W. R. Pitner, C. L.Hussey, J. Electrochem. Soc. 144 (1997) 3095-3103.

[6] M. Morimitsu, Y. Nakahara, Y. Iwaki, M. Matsunaga, J. Mining and Metall. 39 (2003) 5967.

[7] S. Zein El Abedin, N. Borissenko, F. Endres, Electrochem. Commun. 6 (2004) 510-514.

[8] F. Endres, A. P. Abbott, D. R. MacFarlane (Eds.), Electrodeposition from Ionic Liquids, John Wiley and Sons Ltd. Wiley-VCH, 2008.

[9] B. Garcia, S. Lavallée, G. Perron, C. Michot, M. Armand, Electrochimica Acta. 49 (2004) 4583-4588.

[10] Y. Katayama, S. Dan, T. Miura, T. Kishi, J. Electrochem. Soc. 148 (2001) C102.

[11] P. He, H. T. Liu, Z. Y. Li, Y. Liu, X. D. Xu, J. H. Li, Langmuir 20 (2004) 10260.

[12] P. He, H. Liu, Z. Li, H. Li, J. Electrochem. Soc. 152 (2005) E146.

[13] H.-F Huang, I.-X. Sun, Electrochim. Acta 49 (2004) 3251.

[14] D. R. MacFarlane, N.Tachikawa, M.Forsyth, J M. Pringle, P. C. Howlett, G. D. Elliott, J. H. Davis, Jr., M. Watanabe, P. Simon, C. A. Angell, Energy applications of ionic liquids. Energy \& Environmental Science, 7(1) (2014) pp. 232-250. ISSN 1754-5692.

[15] K. Matsumoto, R. Takini, T. Nohira, R. Hagiwara, ECS Transaction 64(4) (2014) 433438.

[16] M. Marszalek, Z. Fei, D. R. Zhu, R. Scopelliti, P. J. Dyson, S .M. Zakeeruddin, M. Grätzel, Inorg. Chem. 50 (2011) 11561-11567.

[17] L. H. S. Gasparotto, N. Borisenko, N. Bocchi, S. Zein El Abedin, F. Endres, Phys. Chem. Chem. Phys. 11 (2009) 11140.

[18] B. C. M. Martindale, S. E. Ward Jones, R. G. Compton, Phys. Chem. Chem. Phys. 12 (2010) 1827-1833.

[19] M. C. Buzzeo, R. G. Evans, R. G. Compton, Chem. Phys. Chem. 5 (2004) 1106.

[20] P.Y. Chen, C.L. Hussey, Electrochim. Acta. 52 (2007) 1857.

[21] Y. Chen, C. Davoisne, J. M. Tarascon, C. Guéry, J. Mater. Chem. 22 (2012) 5295. 
[22] T. Katase, K. Murase, T. Hirato, Y. Awakura, J. Appl. Electrochem. 37 (2007) 339.

[23] X. Xu, C. L. Hussey, J. Electrochem. Soc. 140 (1993) 618-626.

[24] J. F. Huang, I.W. Sun, J. Electrochem. Soc. 150 (2003) E299.

[25] K. R. Seddon, A. Stark, M. J. Torres, Pure. Appl. Chem., 72 (2000) 2275-2287.

[26] W. Yang, H. Cang, Y. Tang, J. Wang, Y. Shi, J. Appl. Electrochem. 38 (2008) 537-542.

[27] P. Y. Chen, C. L. Hussey, Electrochim. Acta 46 (2001) 1169.

[28] A. P. Abbott, G. Capper, K. J. McKenzie, K. S. Ryder, K. S. J. Electroanal. Chem. 288 (2007) 599.

[29] J.-F. Huang , I.-W. Sun , J. Electrochem. Soc. 149 (2002) E348.

[30] H. Groult, H. El Ghallali, A. Bahoun, E. Briot, S. Hernandovena, F. Lantelme, Electrochim. Acta 55 (2010) 1926-1932.

[31] H. El Ghallali, H. Groult, A. Bahoun, K. Draoui, D. Krulic, F. Lantelme, Electrochim. Acta 54 (2009) 3152-3160.

[32] S. V. Dzyuba, R. A. Bartsch, Chem. Phys. Chem. 161 (2002) 6.

[33] H. A. Every, A. G. Bishop, D. MacFarlane, G. Orädd, M. Forsyth, Phys. Chem. Chem. Phys. 6 (2004) 2103.

[34] P. Bonhôte, A.-P. Dias, N. Papageorgiou, K. Kalyanasundaram, M. Grätzel, Inorg. Chem. 35 (1996) 1168-1178.

[35] B. D. Fitchett, T. N. Knepp, J. C. Conboy, J. Electrochem. Soc. 151 (2004) E219.

[36] H. Tokuda, K. Hayamizu, K. Ishii, M. A. B. H. Susan, J. Watanabe, J. Phys. Chem. B 109 (2005) 6103.

[37] J. G. Huddleston, A. E. Visser, W. M. Reichert, H. D. Willauer, G. A. Broker, R. D. Rogers, Green Chem.3 (2001) 156-164.

[38] T. I. Leong, Y. T. Hsieh, I. W. Sun, Electrochimica Acta 56 (2011) 3941-3946.

[39] www.solvionic.com.

[40] S. Isobel Fletcher, F. B. Sillars, N. E. Hudson, P. J. Hall, J. Chem. Eng. Data., 55 (2010) 778-782.

[41] P. Trulove, R. Mantz, (2003) in Ionic Liquids in Synthesis (P. Wasserscheid and T. Welton, eds), Wiley-VCH, Verlag GmbH, pp. 112-116.

[42] K.R. Seddon, A. Stark, M.J. Torres, Am. Chem. Soc., Symp. Ser., 819 (2002) 34-49.

[43] T.-L Leong, I.-W. Sun, M.-J. Deng, C.-M. Wu, P.-Y. Chen, J. Electrochem. Soc. 155 (2008) F55.

[44] V. Gutmann, The Donor-Accepter Approach to molecular interactions, Plenum Press, New York, 1978.

[45] M. Yamagata, Y. Katayama, T. Miura, J. Electrochem. Soc. 153 (2006) E5. 
[46] T. A. Zawodzinski Jr., R. A. Osteryoung, Inorg. Chem. 28 (1989) 1710.

[47] K Murase, K. Nitta, T. Hirato, Y. Awakura, J. Appl. Electrochem. 31 (2011) 1089-1094.

[48] T. Katase, K. Murase, T. Hirato, Y. Awakura, J. Appl. Electrochem. 37 (2007) 339-344.

[49] http://www.metallurgy.nist.gov/phase/solder/cusn.html

[50] W. Biltz, Z. Anorg. Allg. Chem. 134 (1924) 25-36.

[51] D. Li, P. Franke, S. Fürtauer, D. Cupid , H. Flandorfer, Intermetallics 34 (2013) 148-158. 


\section{Figures caption}

Table 1. Physico-chemical properties obtained at $25^{\circ} \mathrm{C}$ of the different RTILs. $\mu$, dynamic viscosity; $\rho$, density; $\kappa$, conductivity, $\mathrm{T}_{\text {decomp. }}$, decomposition temperature.

Table 2. Comparison of the physico-chemical properties of the RTILs. Data obtained at $25^{\circ} \mathrm{C}$.

Table 3. Evolution of the diffusion coefficient of Sn(II) in the RTILs containing $0.01 \mathrm{~mol} \mathrm{~L}^{-1}$ of $\mathrm{Sn}$ (II) $v s$. temperature.

Table 4. $\mathrm{D}_{0}$ and $\mathrm{E}_{\mathrm{a}}$ in the three RTILs containing $0.01 \mathrm{~mol} \mathrm{~L}^{-1}$ of $\mathrm{Sn}(\mathrm{II})$ at $25^{\circ} \mathrm{C}$.

Fig. 1. Electrochemical cell used for the anodic dissolution of $\mathrm{Sn}$ or $\mathrm{Cu}$.

Fig. 2. Variation of the density, $\rho$, of RTILs vs. T for the various RTILs

Fig 3a. Variation of the conductivity, $\kappa$, vs. 1/ T for the various RTILs.

Fig 3b. Variation of the dynamic viscosity, $\mu$ vs. $1 / \mathrm{T}$ for the various RTILs.

Fig. 4. Cyclic voltammogram recorded in BMP-NTf 2 using a Pt working electrode at $25^{\circ} \mathrm{C}$. Reference electrode: Pt wire. Scan rate: $50 \mathrm{mV} / \mathrm{s}$.

Fig.5. Variation of the free potential measured with a Sn electrode in EMI-NTf 2 vs. Sn(II) content. $\mathrm{T}=25^{\circ} \mathrm{C}$.

Fig. 6a. Cyclic voltamogramm obtained with a Pt working electrode in $0.01 \mathrm{~mol} \mathrm{~L}^{-1} \mathrm{Sn}(\mathrm{II})$ in EMI-NTf ${ }_{2}$ at $25^{\circ} \mathrm{C}$. Reference electrode: Pt wire. Scan rate: $50 \mathrm{mV} / \mathrm{s}$.

Fig. 6b. Cyclic voltamogramms obtained with a Pt working electrode in $0.01 \mathrm{~mol} \mathrm{~L}^{-1} \mathrm{Sn}(\mathrm{II})$ in EMI-NTf $f_{2}$ at various scan rates. $\mathrm{T}=25^{\circ} \mathrm{C}$. Reference electrode: $\mathrm{Pt}$ wire.

Fig. 7. Cyclic voltamogramms obtained with a Pt working electrode in $0.01 \mathrm{~mol} \mathrm{~L}^{-1} \mathrm{Sn}(\mathrm{II})$ BMP-NTf $f_{2}$ at $25^{\circ} \mathrm{C}$. Potential stop: $-0.9 \mathrm{~V}$ vs. Pt. Reference electrode: Pt wire. Scan rate: $50 \mathrm{mV} / \mathrm{s}$.

Fig. 8. Evolution of the capacity deduced from the surface area under the oxidation peak with time in BMP-NTf $f_{2}$ containing $0.01 \mathrm{~mol} \mathrm{~L}^{-1}$ of $\mathrm{Sn}(\mathrm{II})$ at $25^{\circ} \mathrm{C}$. Potential stop: $-0.9 \mathrm{~V}$ vs. Pt. Reference electrode: $\mathrm{Pt}$ wire. Scan rate: $50 \mathrm{mV} / \mathrm{s}$.

Fig. 9. I-E curves obtained at $25^{\circ} \mathrm{C}$ with a Pt working rotating disk electrode $\left(\mathrm{S}=0.03 \mathrm{~cm}^{2}\right)$ in $0.01 \mathrm{~mol} \mathrm{~L}^{-1} \mathrm{Sn}(\mathrm{II})$ EMI-NTf 2 . Scan rate $=5 \mathrm{mV} \mathrm{s}^{-1}$.

Fig. 10. Variation of $\mathrm{I}_{\mathrm{L}}=f\left(\omega^{-1 / 2}\right)$ obtained with a RDE in $0.01 \mathrm{~mol} \mathrm{~L}^{-1} \mathrm{Sn}(\mathrm{II})$ in EMI-NTf $\mathrm{E}_{2}$ and BMP-NTf $f_{2}$ with a Pt electrode $\left(0.03 \mathrm{~cm}^{2}\right) . \mathrm{T}=25^{\circ} \mathrm{C}$.

Fig. 11. Cyclic voltammograms obtained in $0.01 \mathrm{~mol} \mathrm{~L}^{-1} \mathrm{Sn}(\mathrm{II})$ in EMI-NTf $f_{2}$ for various temperatures. Scan rate: $50 \mathrm{mV} / \mathrm{s}$.

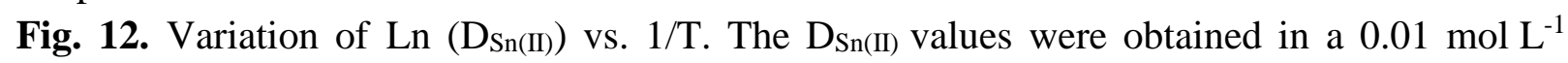
$\mathrm{Sn}$ (II) solution in EMI-NTf 2 , BMP-NTf 2 and EMI- DCA

Fig. 13. SEM images of Sn deposited onto inert Mo substrate in RTILs containing $0.01 \mathrm{~mol} \mathrm{~L}^{-1}$ of $\mathrm{Sn}(\mathrm{II})$; a) BMP-NTf 2 , b) EMI-DCA, and c) EMI-NTf $2 . \mathrm{T}=25^{\circ} \mathrm{C}$.

Fig. 14. XRD patterns of $\mathrm{Sn}$ deposited onto inert Mo substrate in RTILs containing $0.01 \mathrm{~mol} \mathrm{~L}^{-1}$ of $\mathrm{Sn}(\mathrm{II})$; a) in BMP-NTf 2 , b) in EMI-DCA, and c) in EMI-NTf $2 . \mathrm{T}=25^{\circ} \mathrm{C}$.

Fig. 15. Cyclic voltammogram obtained with a Pt working electrode in $0.02 \mathrm{M} \mathrm{Cu}(\mathrm{I})$ EMI-NTf 2 at $25^{\circ} \mathrm{C}$. Scan rate: $50 \mathrm{mV} / \mathrm{s}$. 
Fig. 16. Phase diagram of $\mathrm{Cu}-\mathrm{Sn}$ alloys [Kattner, Ursula (2003). Cu-Sn System. Metallurgy Division of the Materials Science and Engineering Laboratory (MSEL) at the National Institute of Standards and Technology (NIST)]

Fig.17a. SEM images of Sn deposited onto $\mathrm{Cu}$ substrate in EMI-NTf 2 containing $0.01 \mathrm{~mol} \mathrm{~L}^{-1}$ of $\mathrm{Sn}(\mathrm{II})$ at the various temperatures.

Fig. 17b. XRD patterns of $\mathrm{Sn}$ deposited onto $\mathrm{Cu}$ substrate in EMI-NTf 2 at the various temperatures.

Fig. 17c. BEI and EDS of cross-section of deposited $\mathrm{Sn}$ at $25^{\circ} \mathrm{C}$.

Fig. 18. XRD patterns of $\mathrm{Sn}-\mathrm{Cu}$ deposited onto $\mathrm{Cu}$ substrate in EMI-NTf $\mathrm{N}_{2}$ before and after heat-treatment. The ratio of $[\mathrm{Cu}(\mathrm{I})] /[\mathrm{Sn}(\mathrm{II})]=1 / 1$.

Fig. 19a XRD patterns of $\mathrm{Sn}-\mathrm{Cu}$ deposited onto $\mathrm{Cu}$ substrate in EMI-NTf $\mathrm{N}_{2}$ at $25^{\circ} \mathrm{C}$, the annealing at $200^{\circ} \mathrm{C}$ under vacuum.

Fig. 19b. SEM images of $\mathrm{Sn}-\mathrm{Cu}$ deposited onto $\mathrm{Cu}$ substrate in EMI-NTf 2 containing $0.01 \mathrm{~mol} \mathrm{~L}^{-1}$ of $\mathrm{Sn}(\mathrm{II})$ and $0.001 \mathrm{M} \mathrm{Cu}(\mathrm{I})$ at $25^{\circ} \mathrm{C}$, then annealing at $200^{\circ} \mathrm{C}$ under vacuum. The ratio of $[\mathrm{Cu}(\mathrm{I})] /[\mathrm{Sn}(\mathrm{II})]=1 / 10$.

Fig. 19c. BEI and EDS of cross-section of deposited $\mathrm{Sn}-\mathrm{Cu}$ after annealing. 


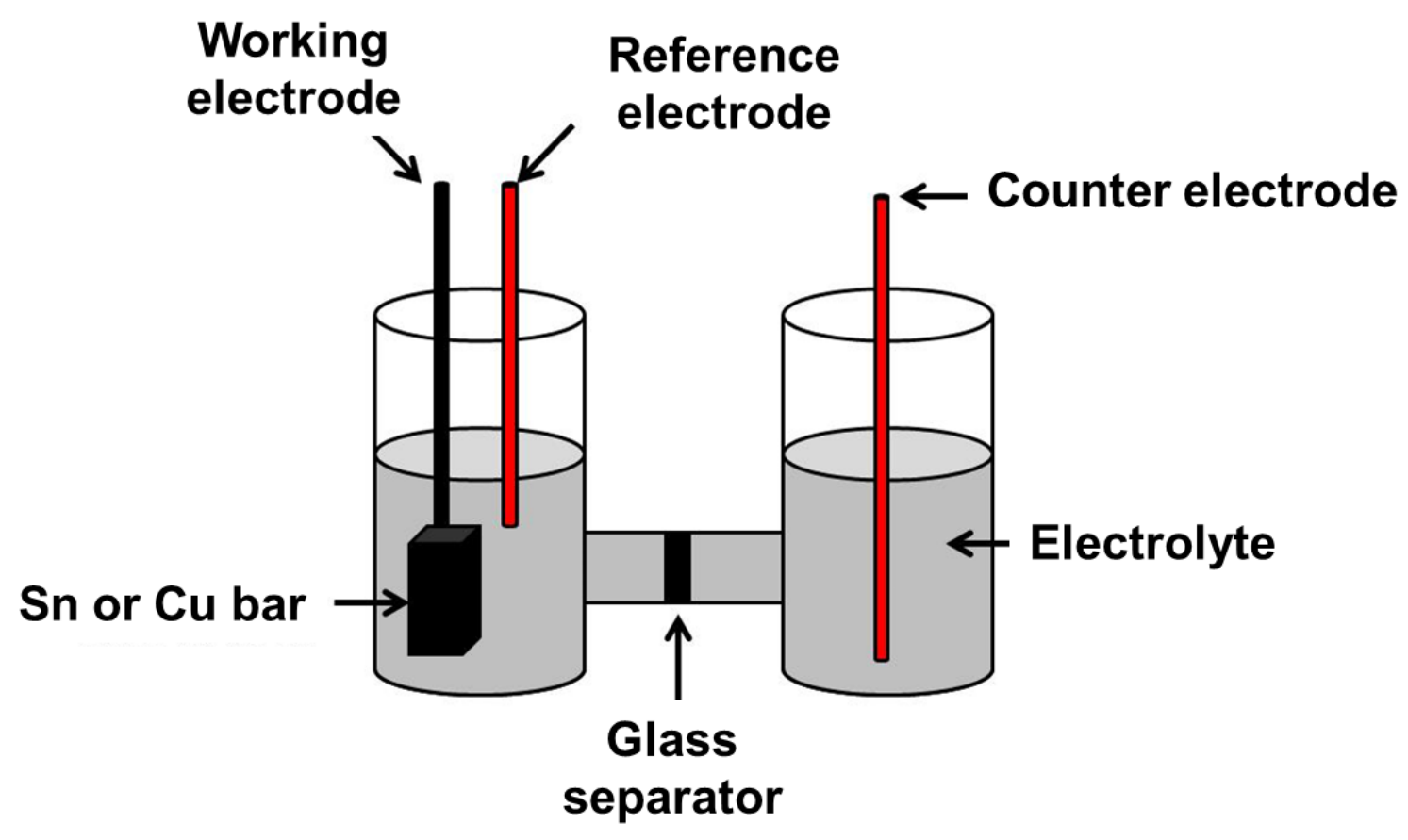

Fig. 1 


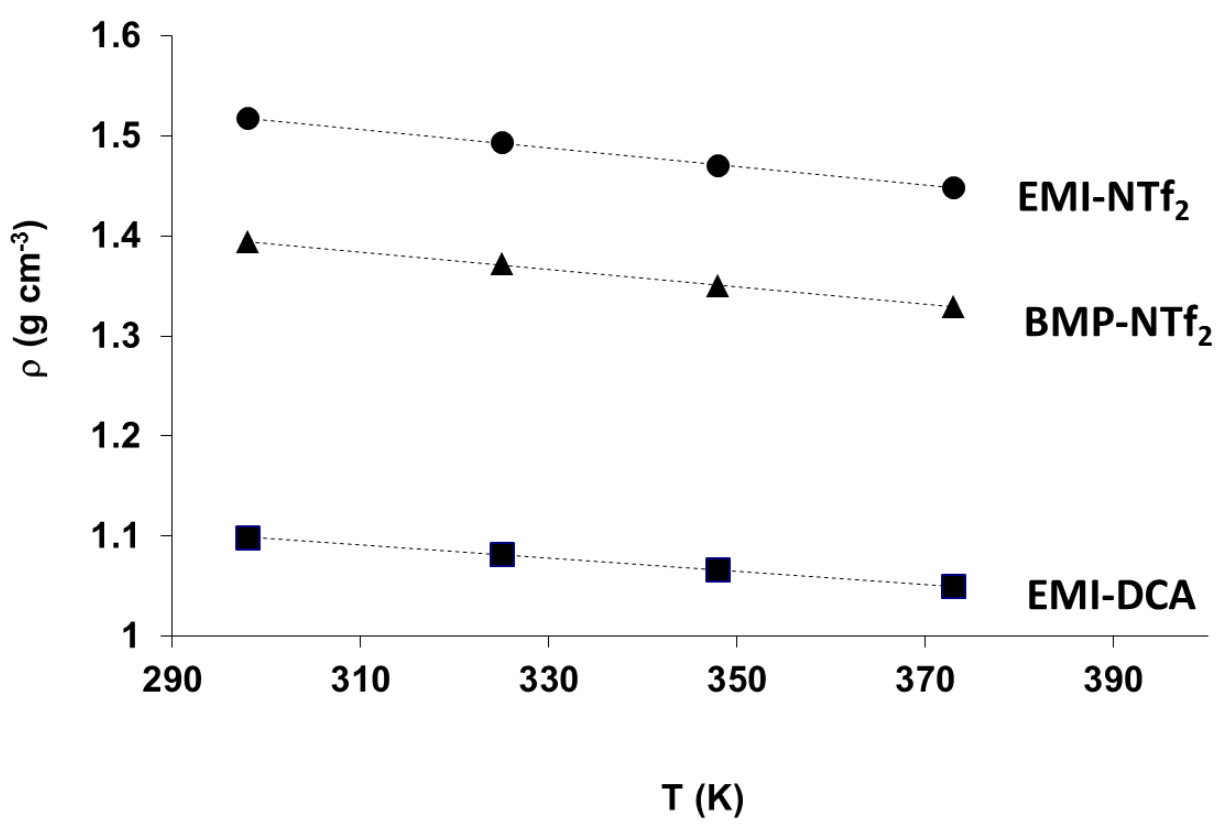

Fig. 2 


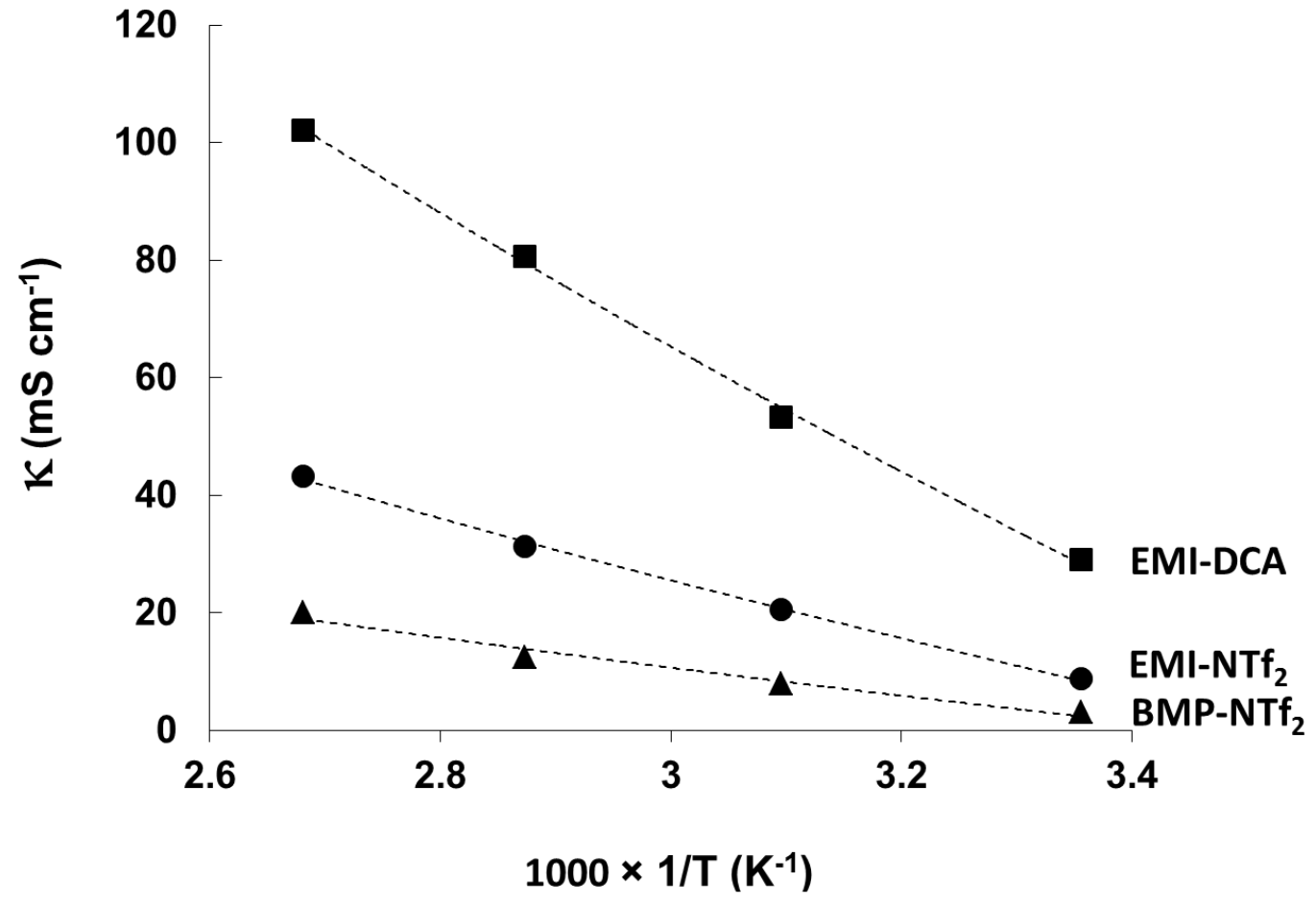

Fig. 3a 


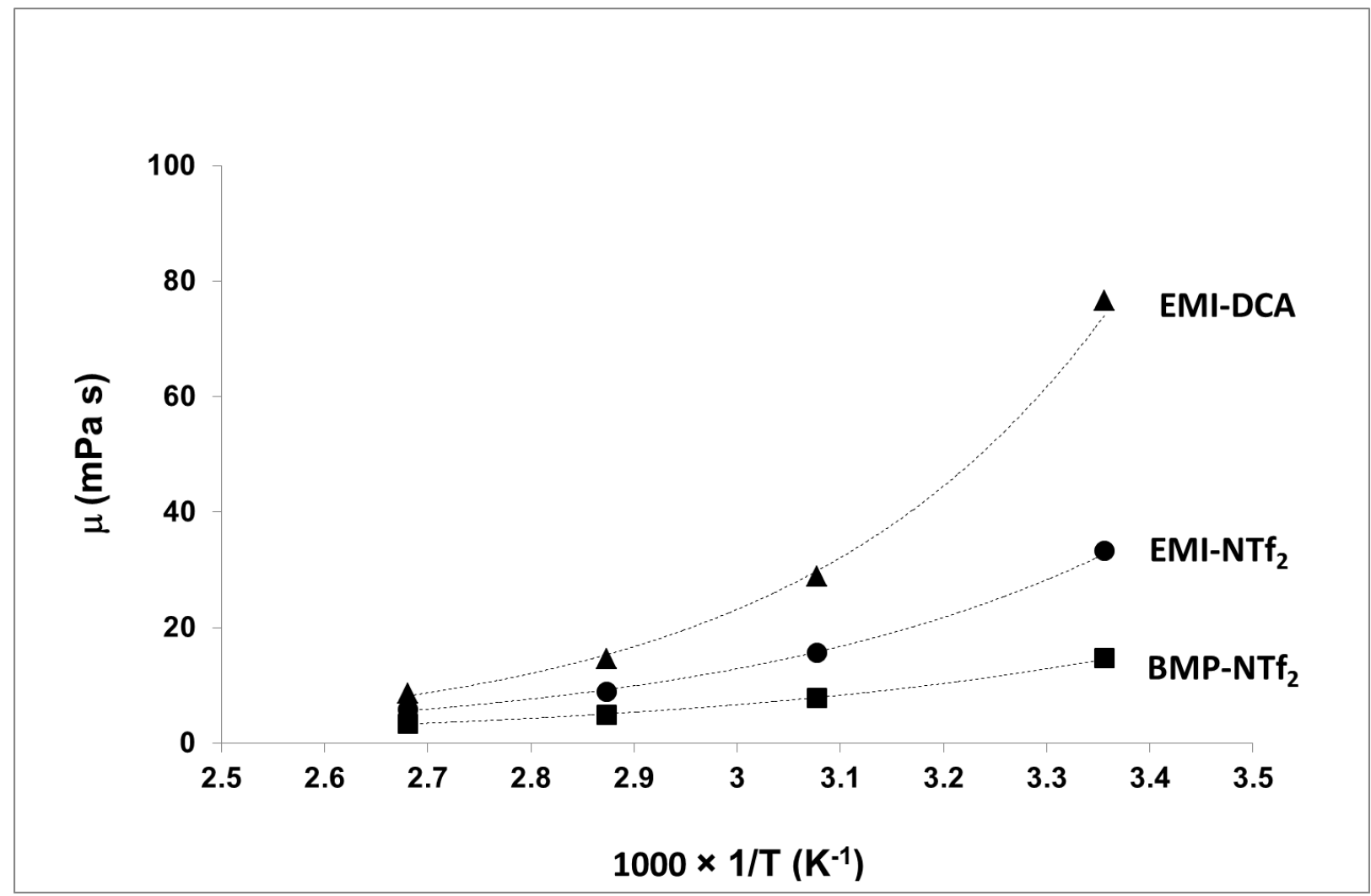

Fig. 3b 


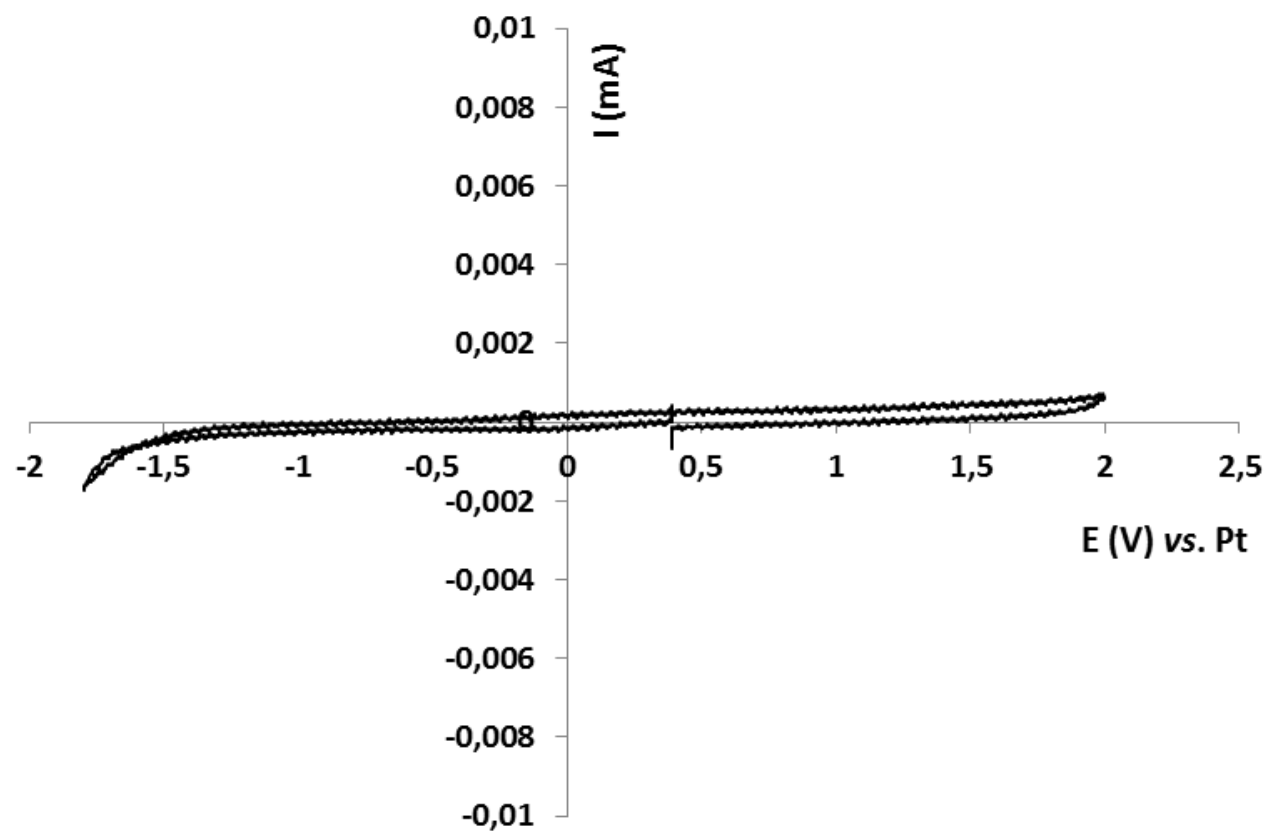

Fig. 4 


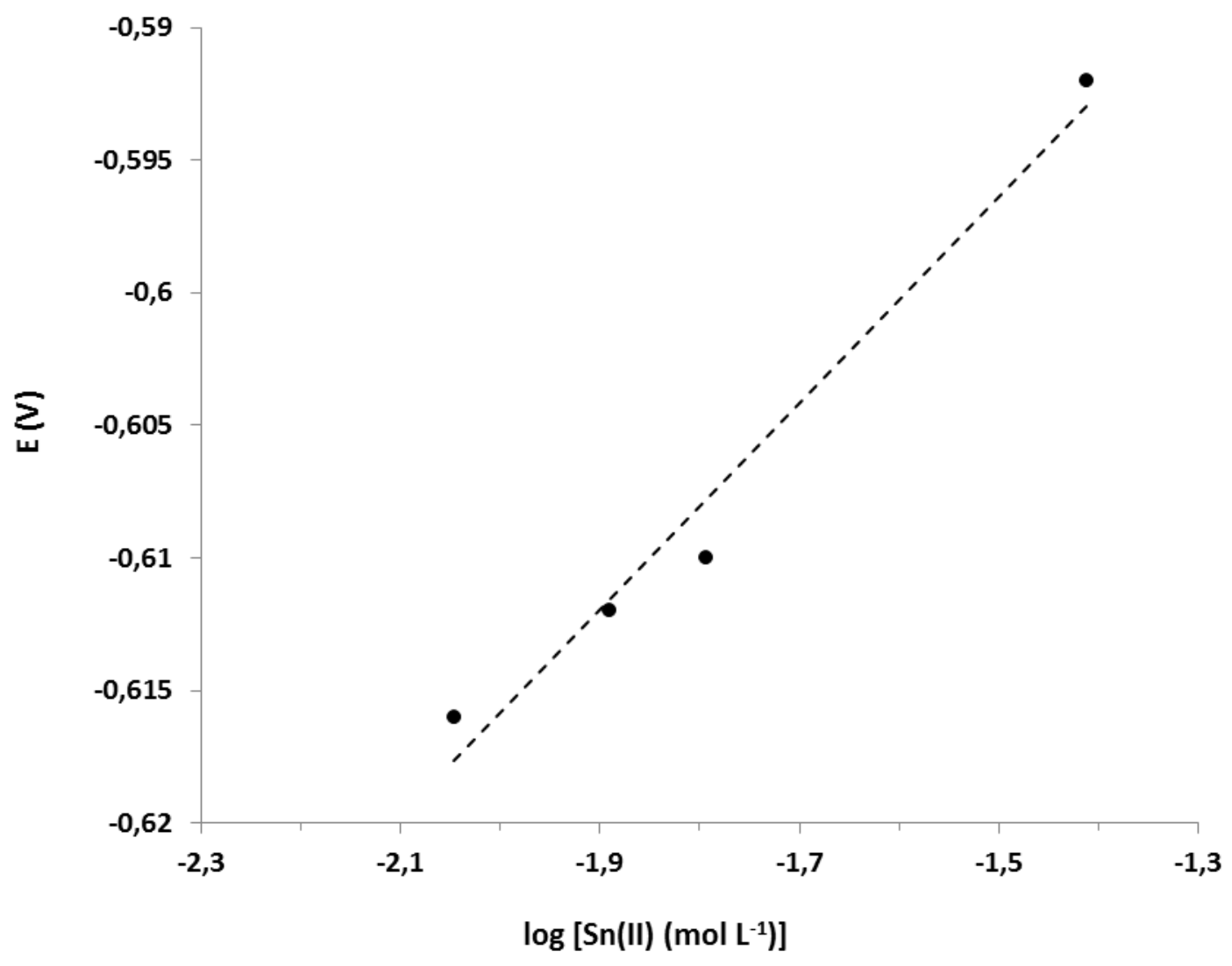

Fig. 5. 


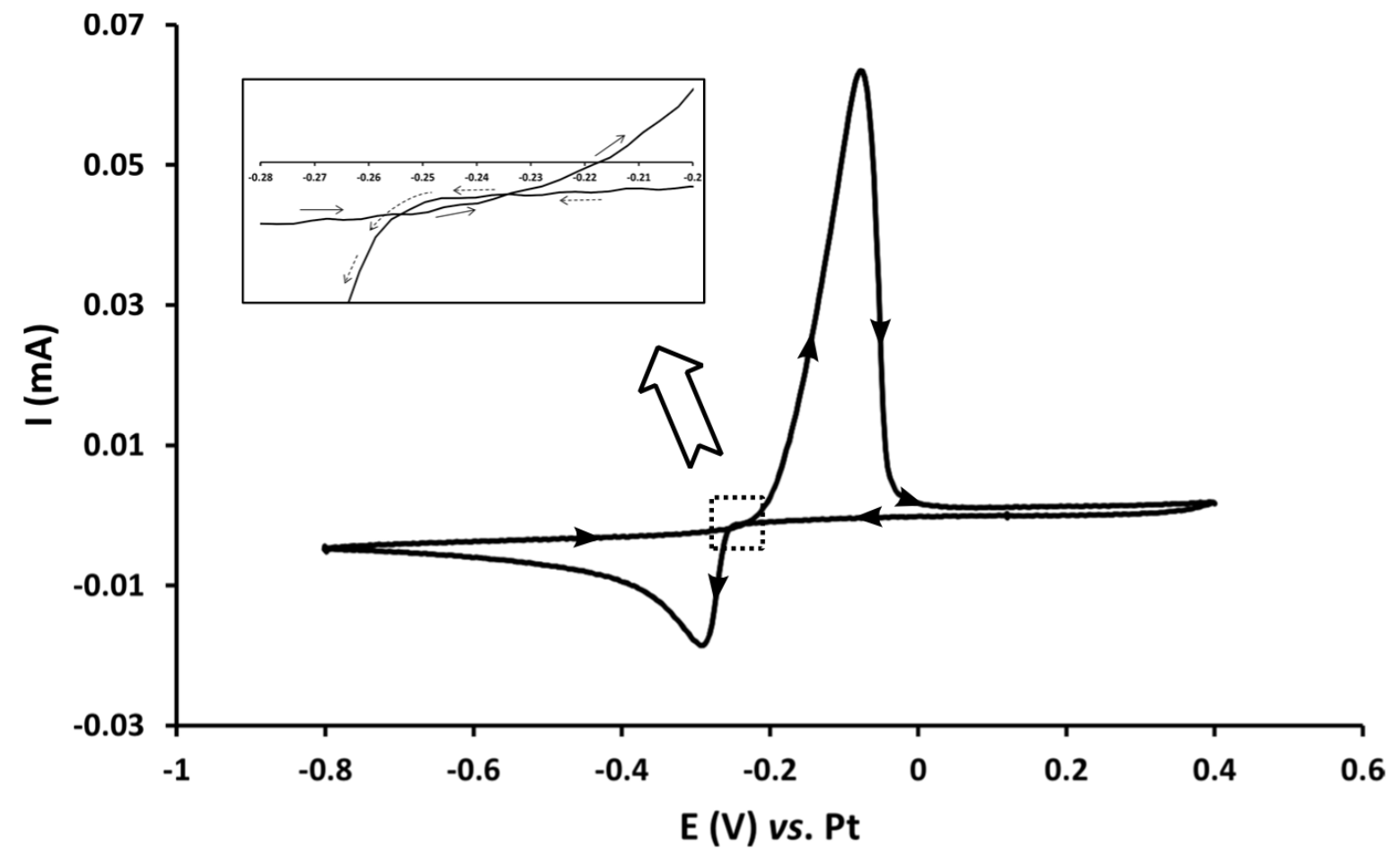

Fig. $6 a$ 


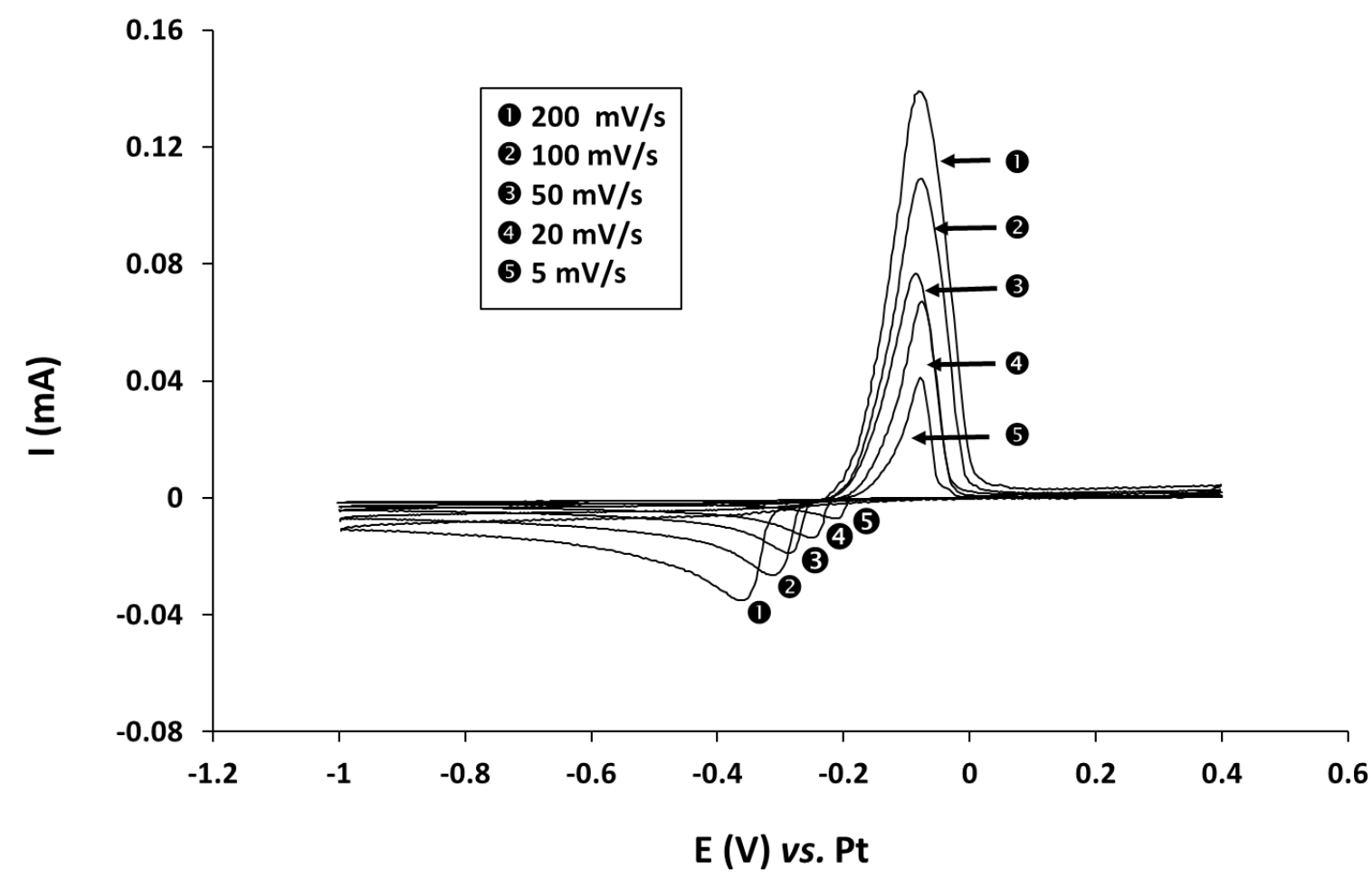

Fig. 6b. 


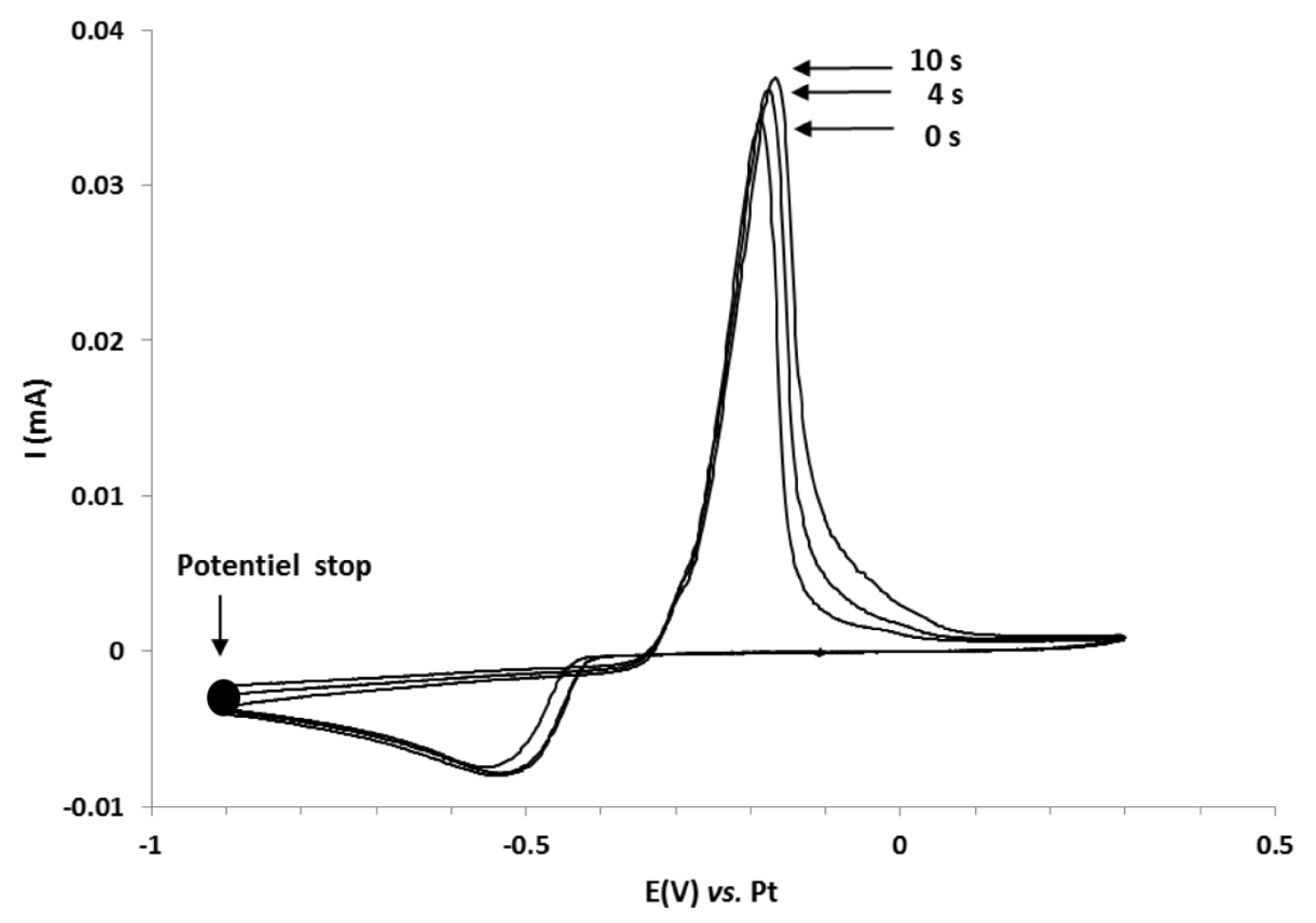

Fig. 7 


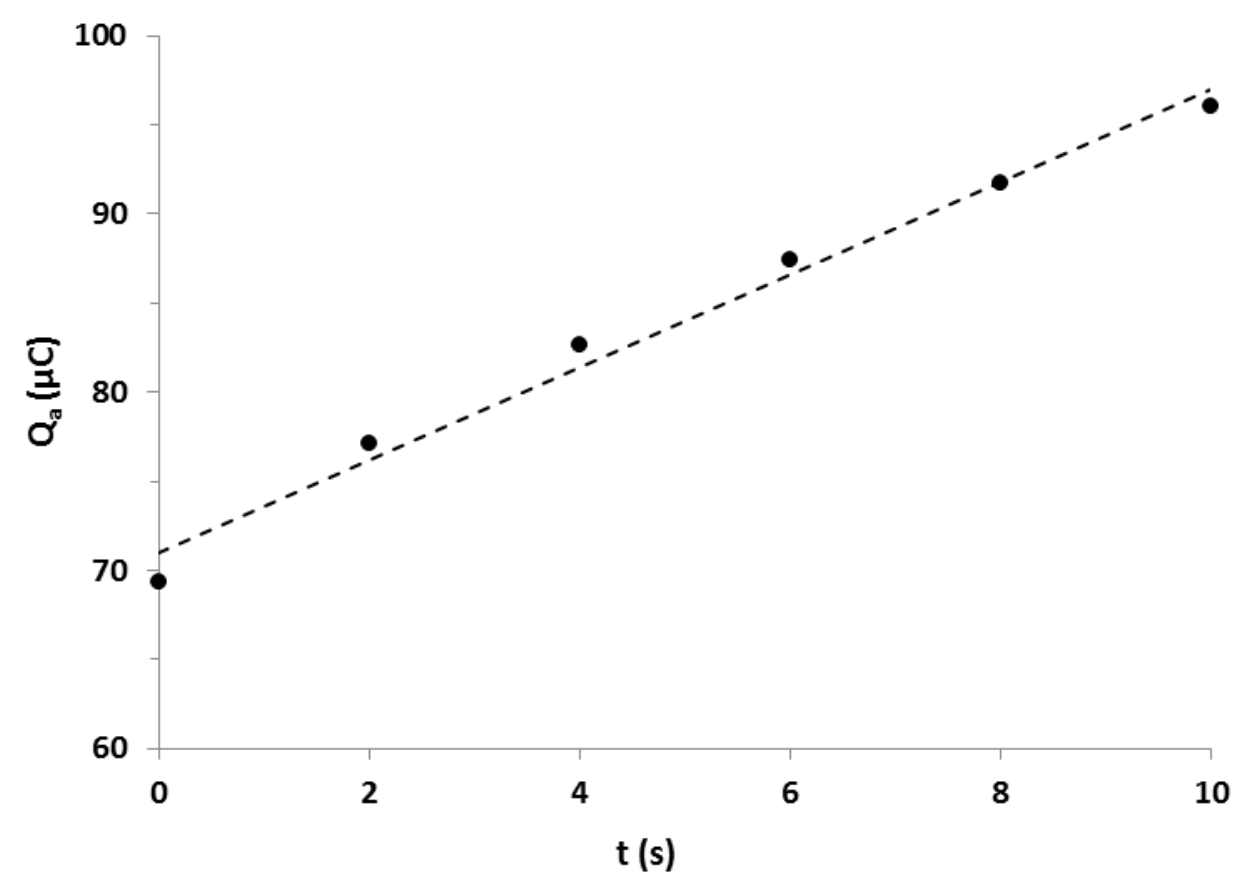

Fig. 8 


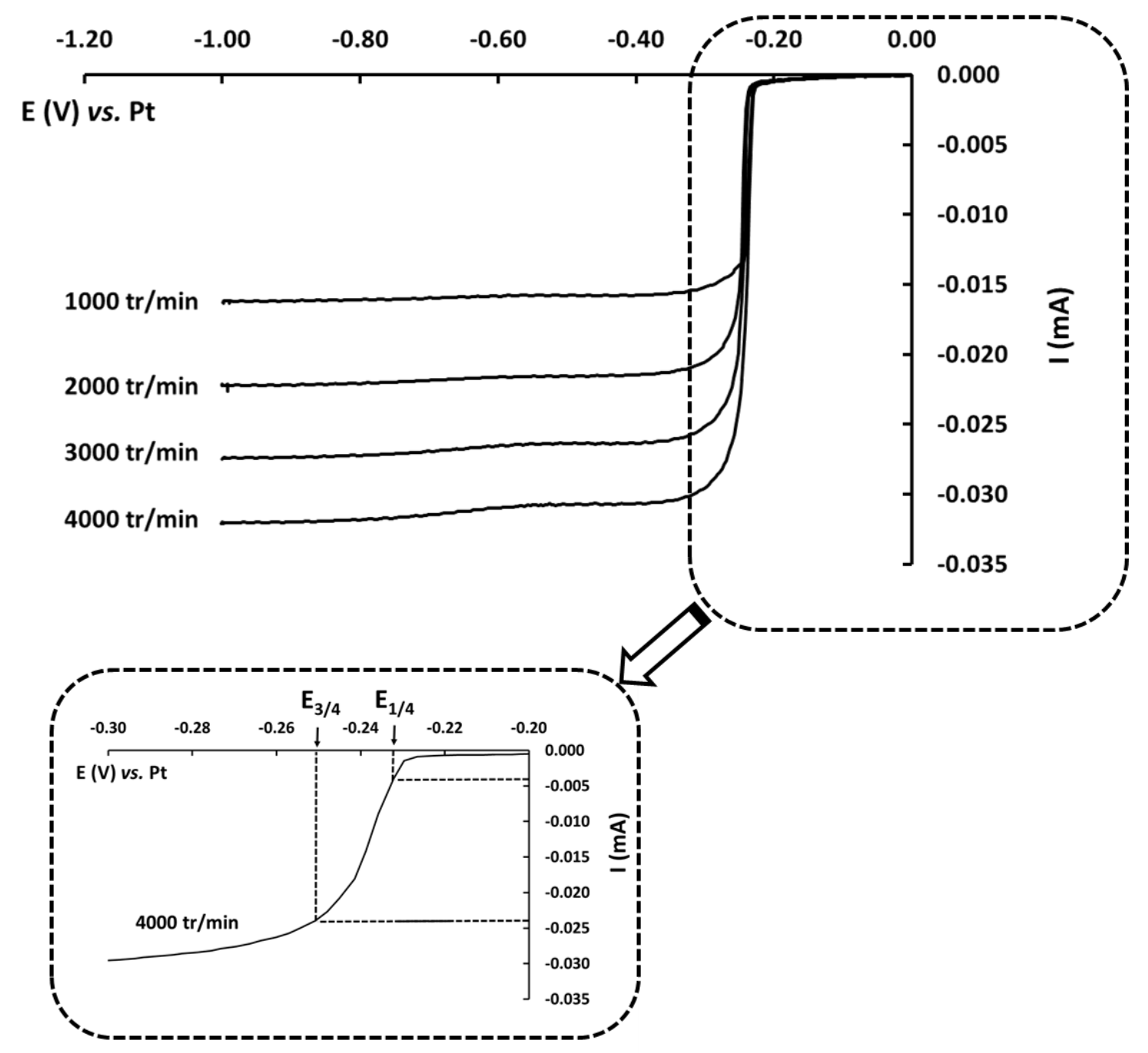

Fig. 9 


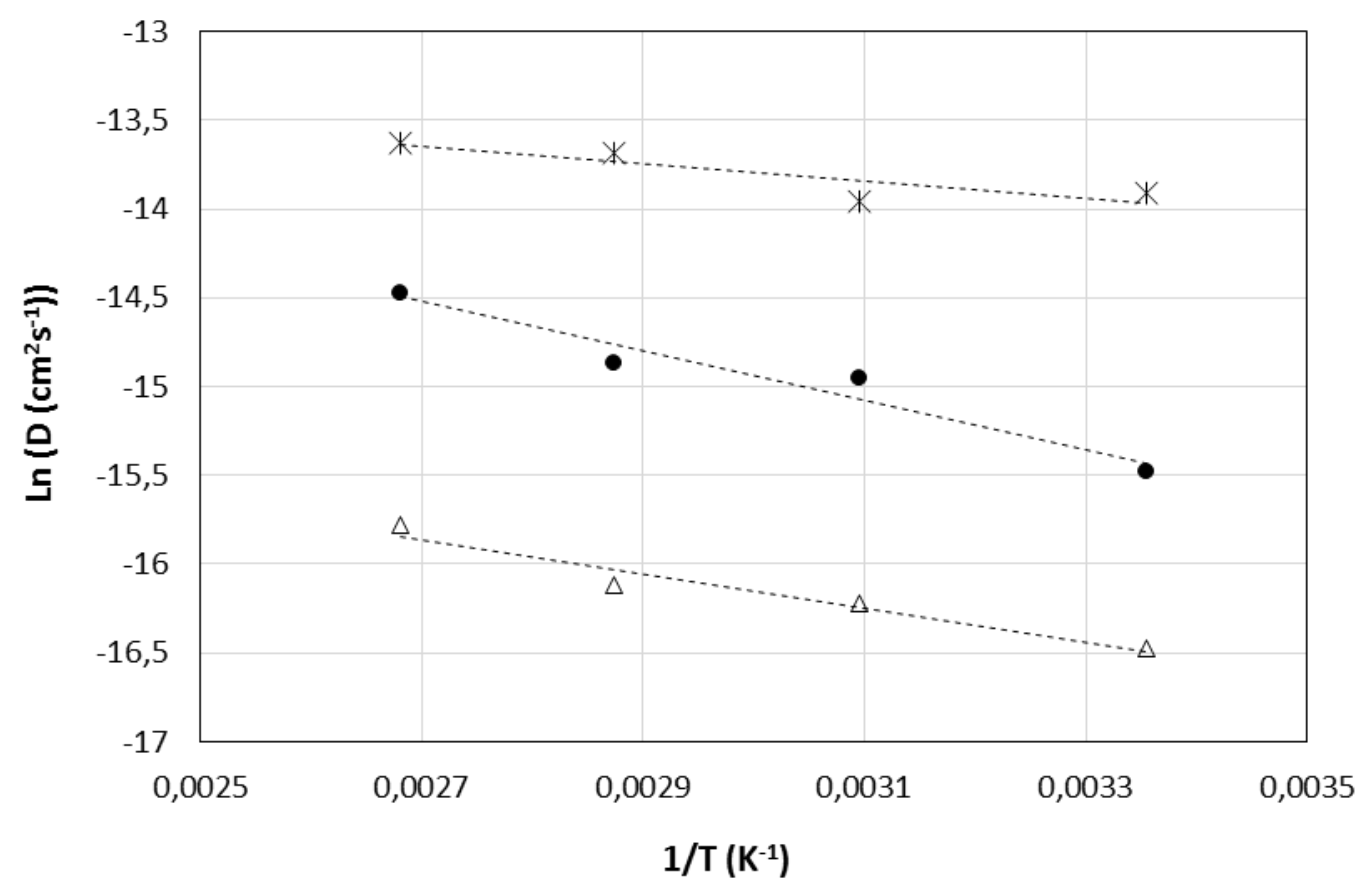

Fig. 10 


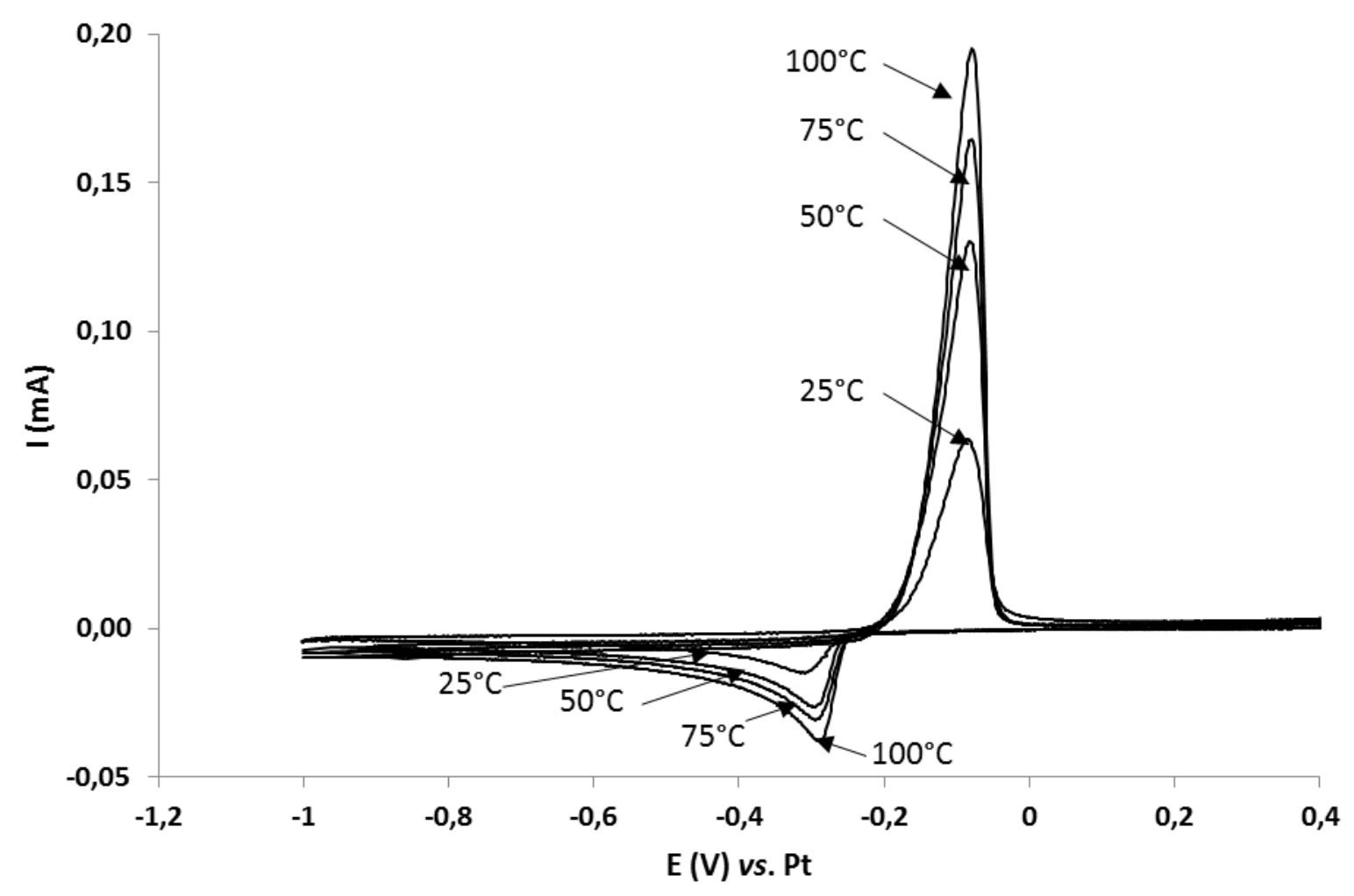

Fig. 11 


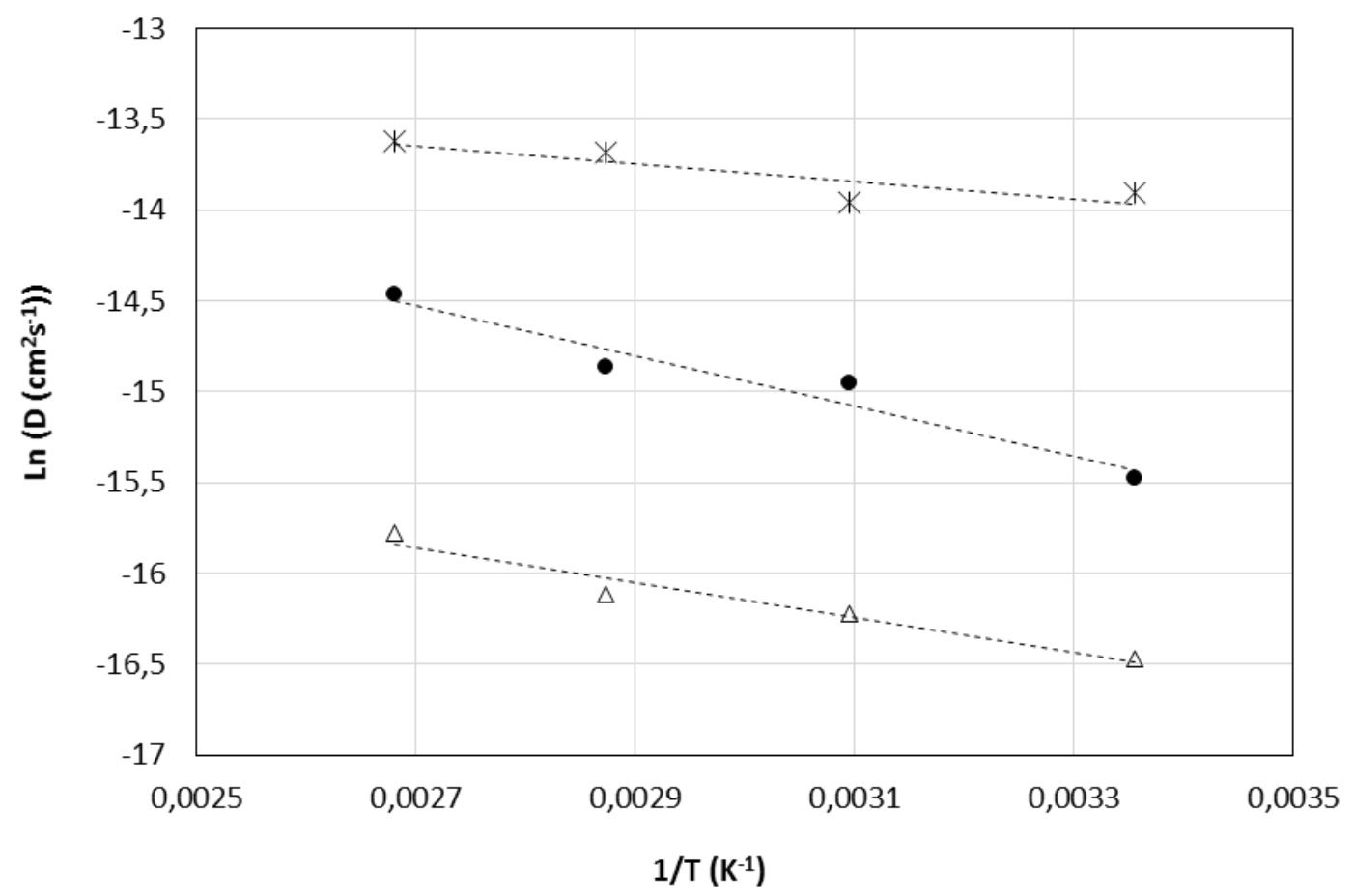

Fig. 12 
A1)

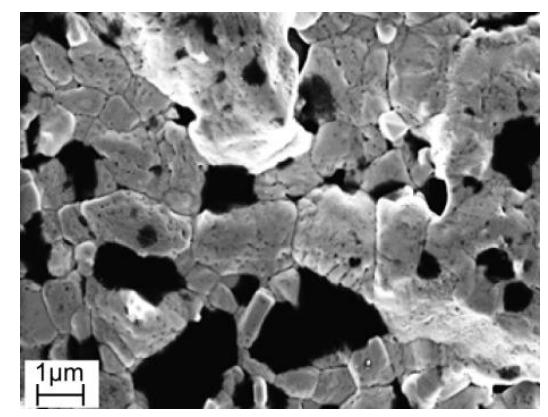

A2)

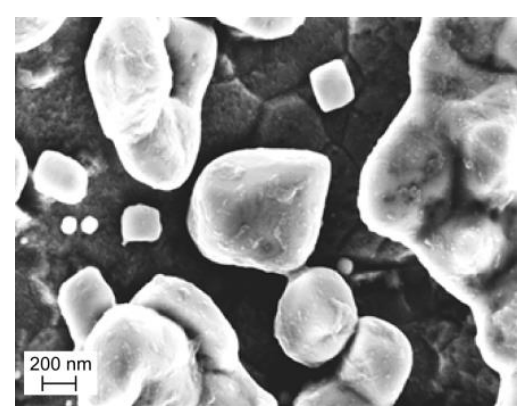

B1)

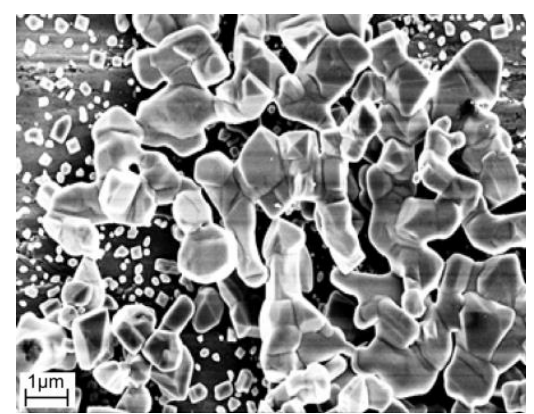

B2)

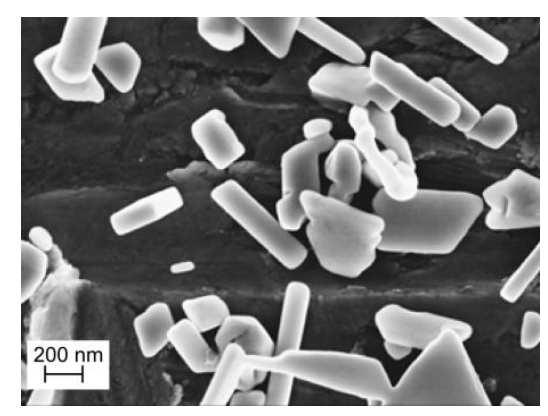

C1)

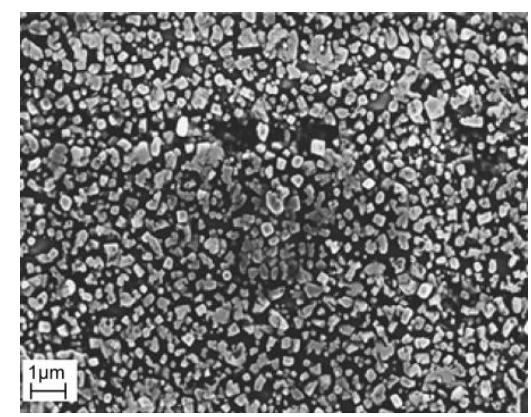

C2)

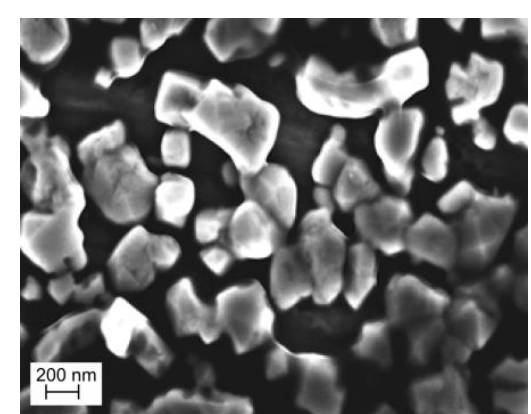

Fig. 13. 


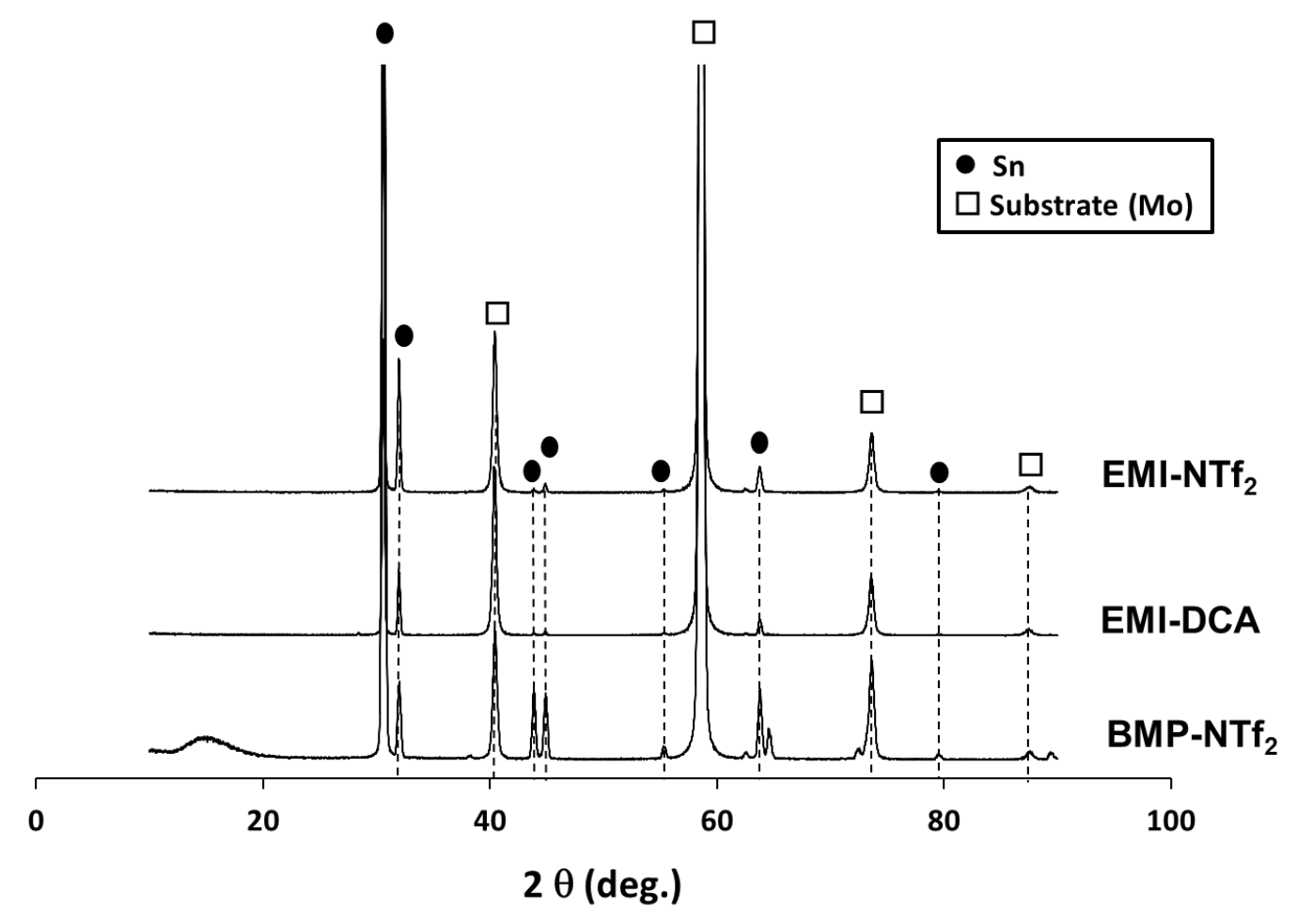

Fig. 14

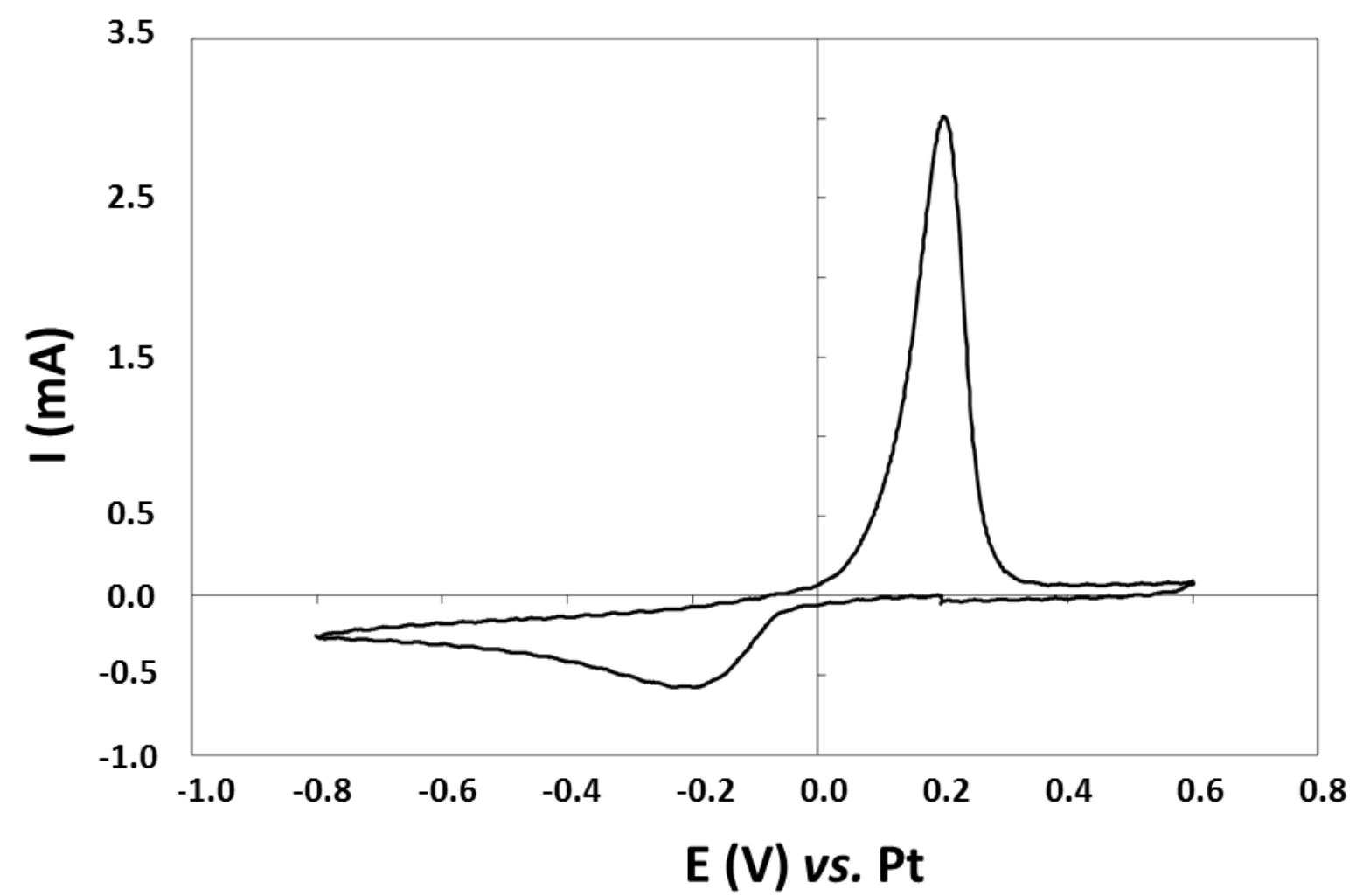


Fig. 15

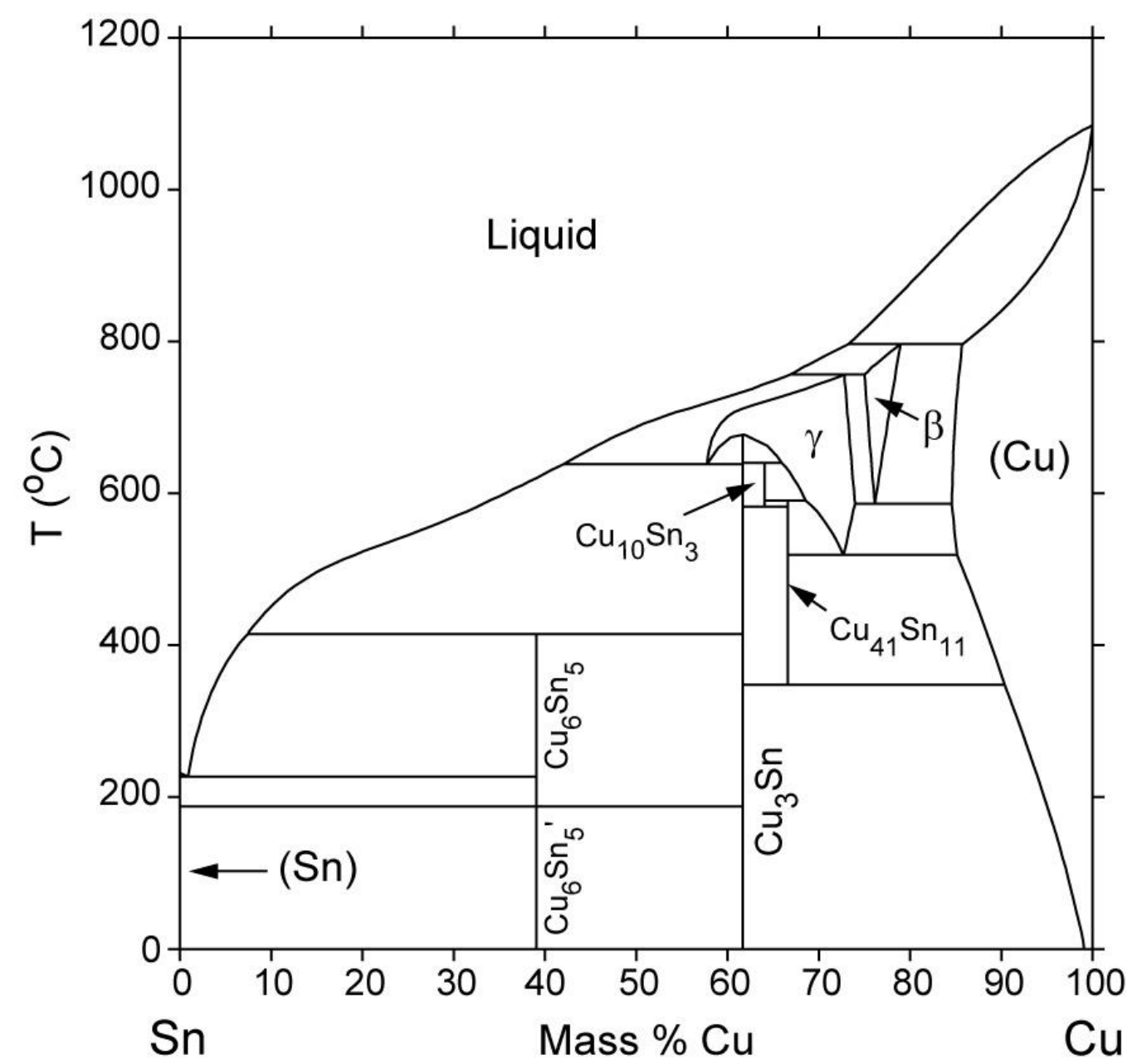

Fig. 16 

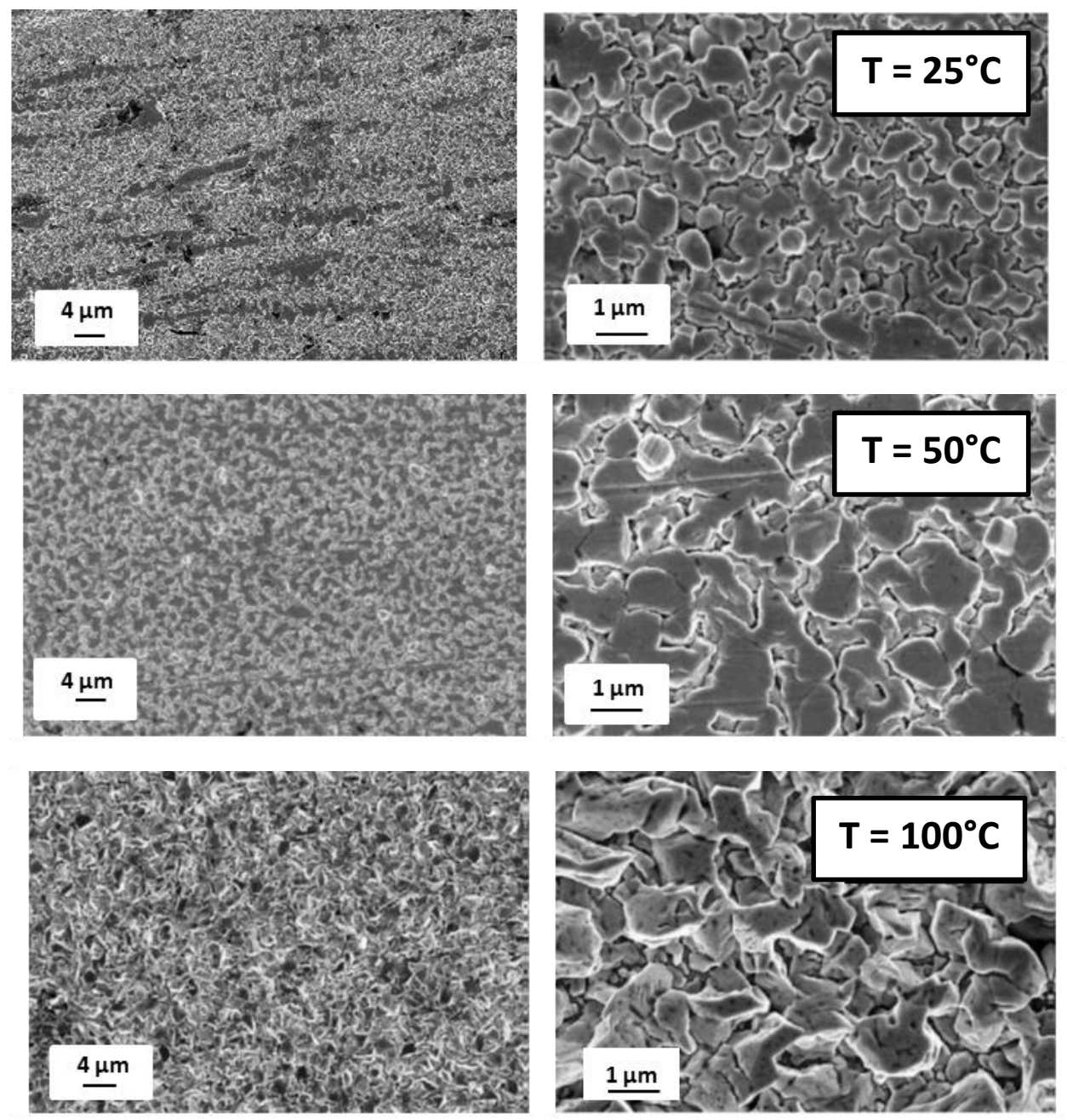

Fig. $17 \mathrm{a}$ 


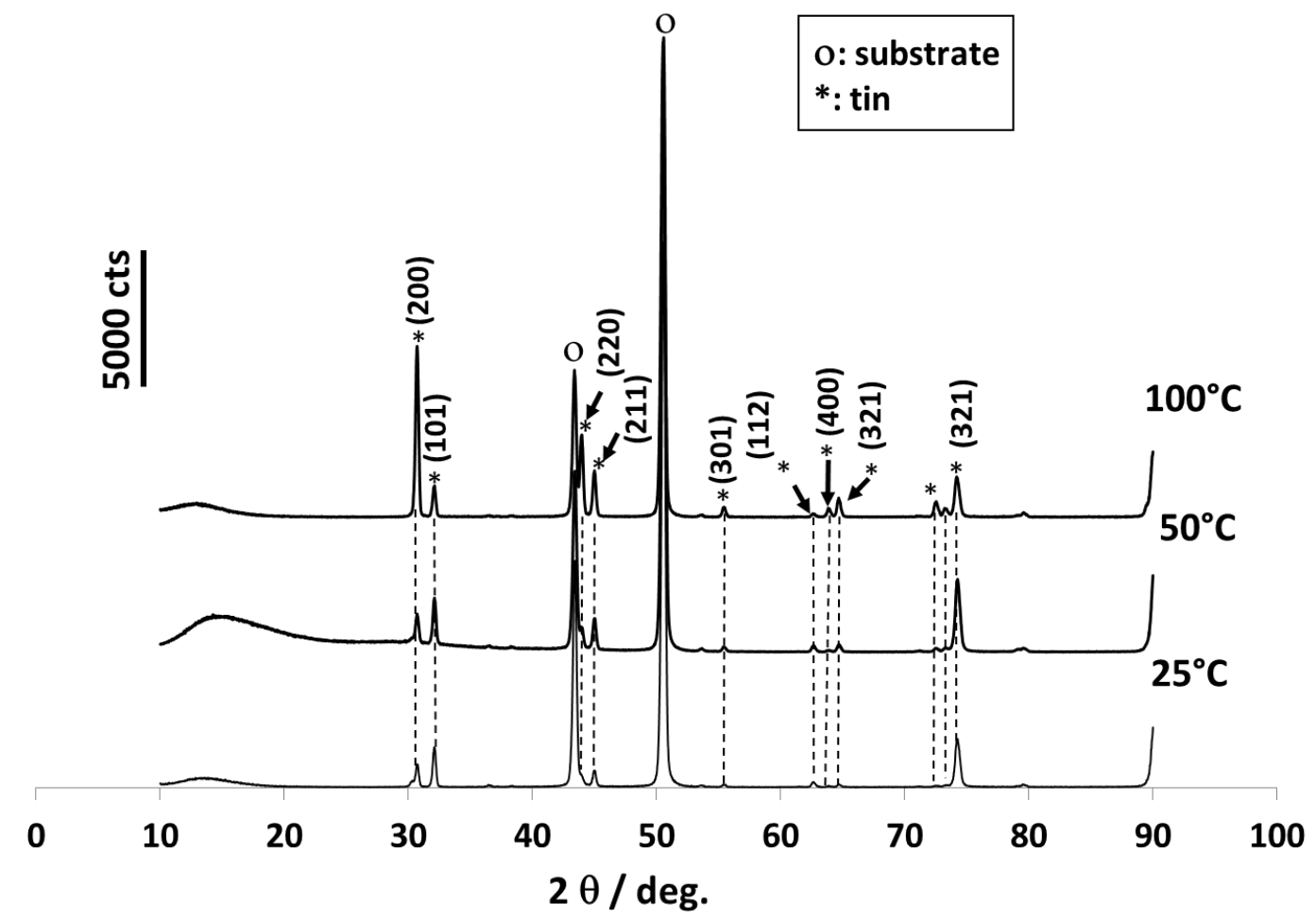

Fig. $17 \mathrm{~b}$ 


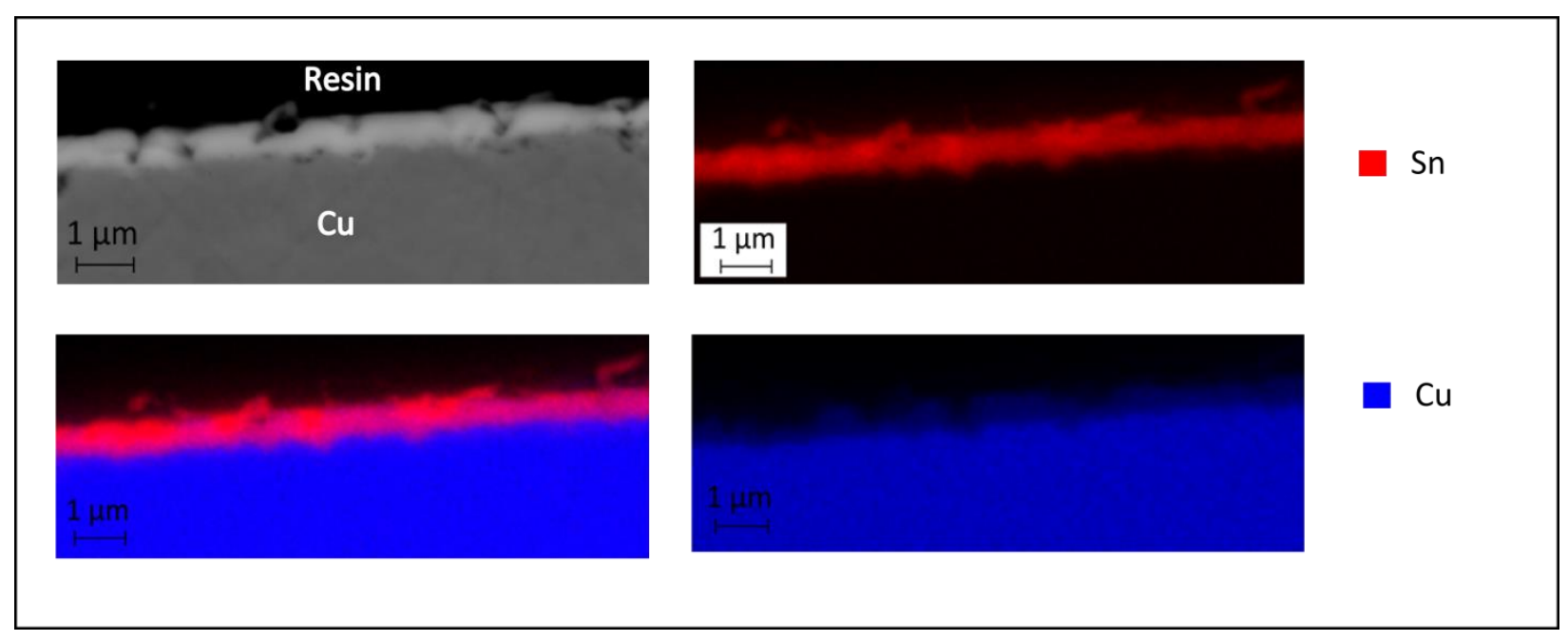

Fig. 17c 


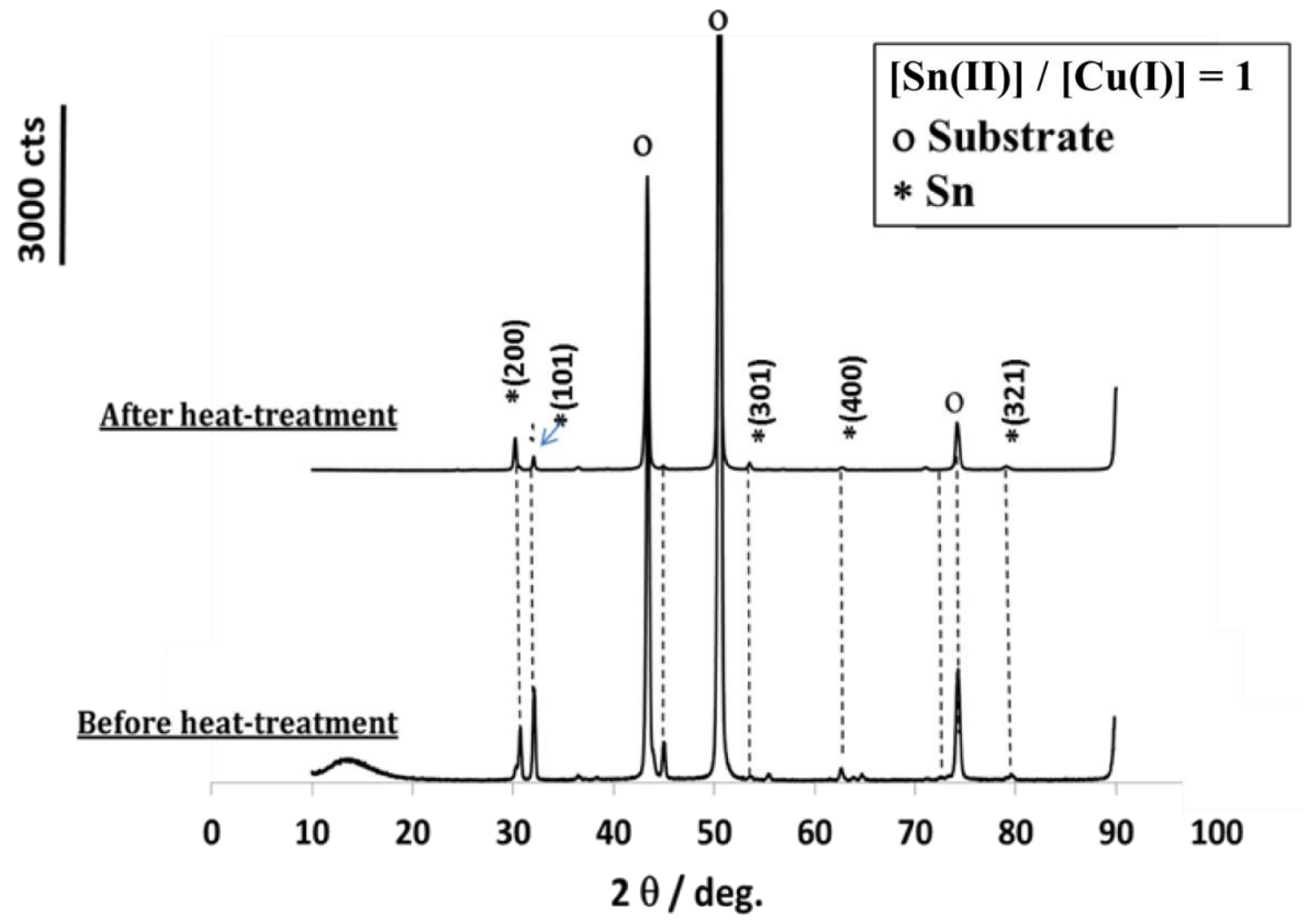

Fig. 18 


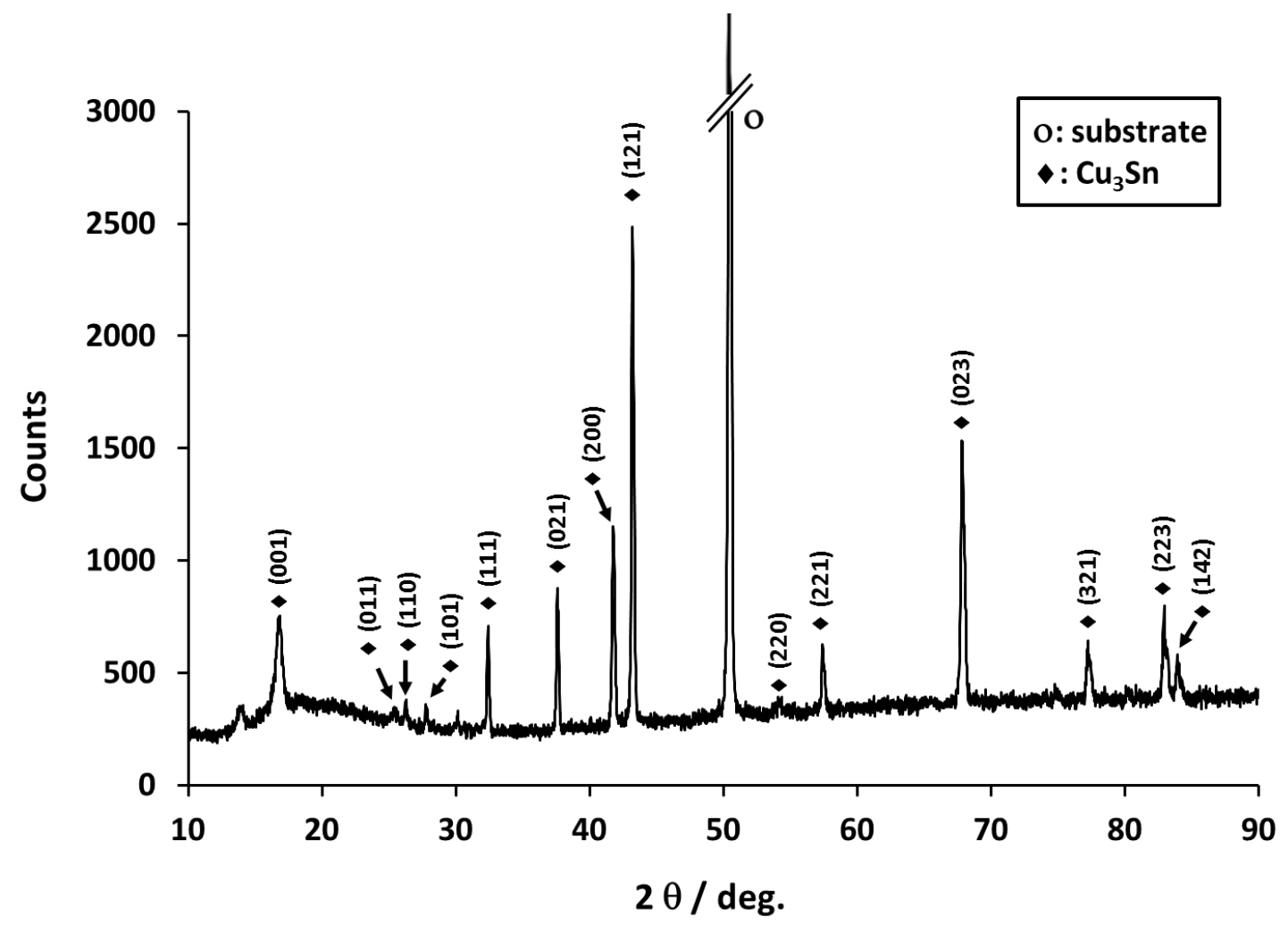

Fig. 19a 


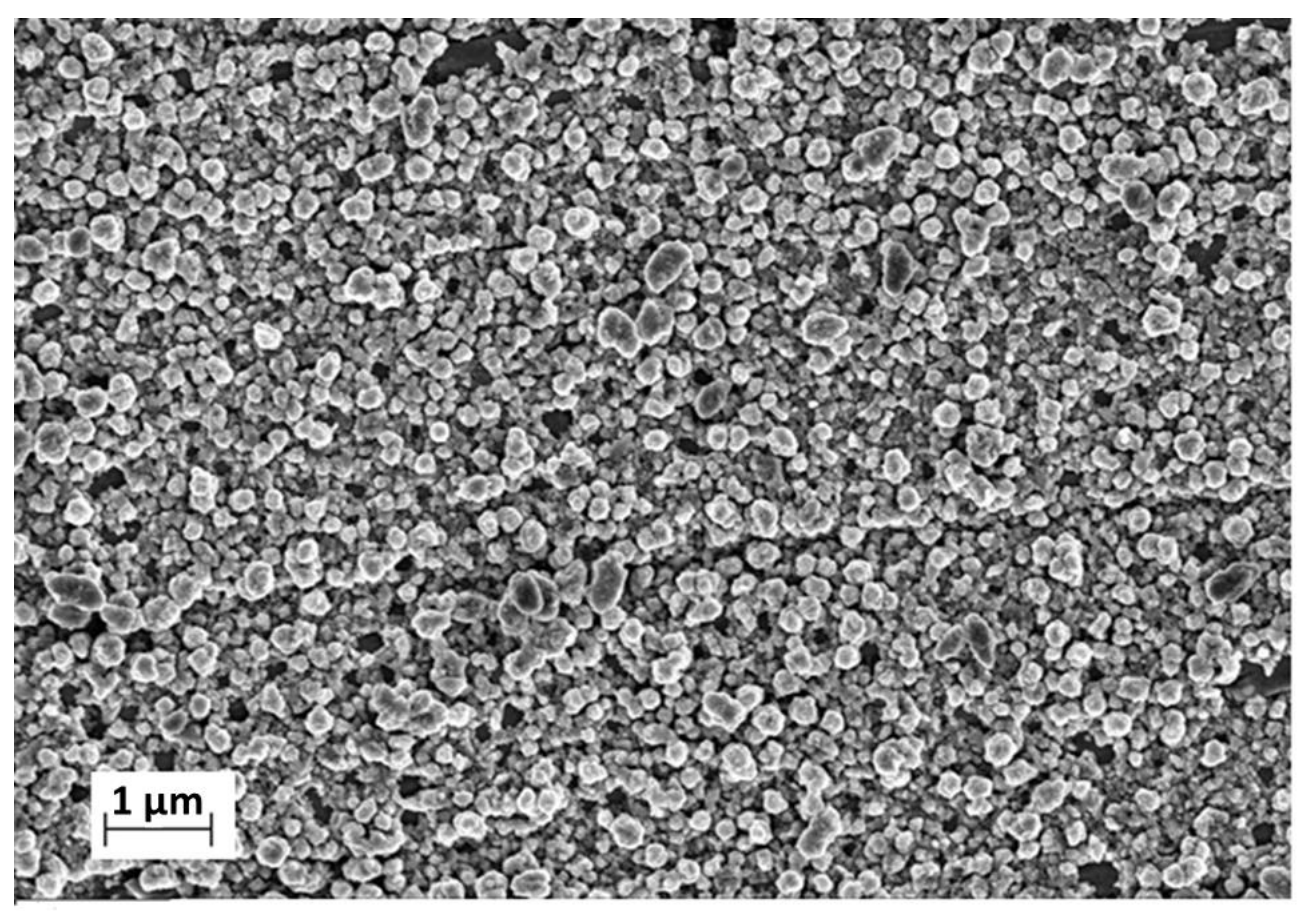

Fig. 19b 


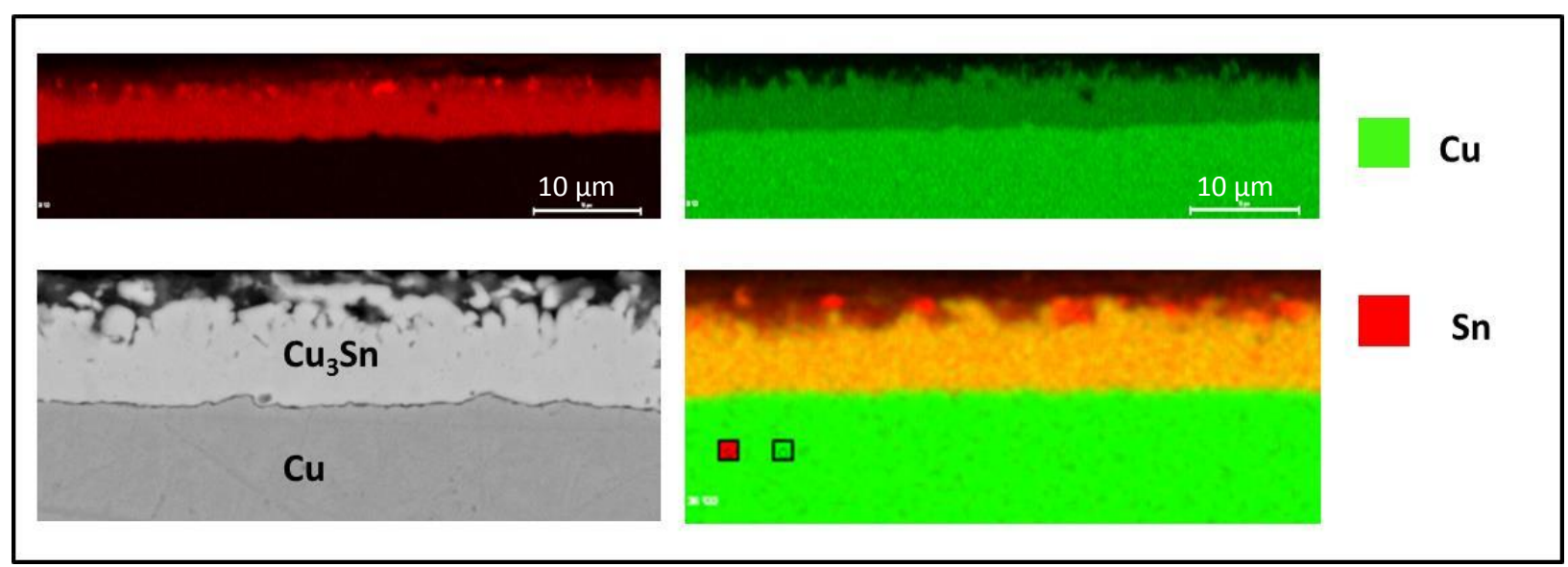

Fig. 19c 